OPEN ACCESS

Edited by:

Bertrand Kaeffer,

Institut National de Recherche pour

l'agriculture, l'alimentation et

l'environnement (INRAE), France

Reviewed by:

Choo Hock Tan,

University of Malaya, Malaysia Kartik Sunagar

Indian Institute of Science (IISC), India

*Correspondence:

Bryan G. Fry

bgfry@uq.edu.au

Specialty section:

This article was submitted to Vaccines and Molecular Therapeutics, a section of the journal

Frontiers in Immunology

Received: 30 September 2020 Accepted: 11 February 2021 Published: 11 March 2021

Citation: Seneci L, Zdenek CN, Chowdhury A

Rodrigues CFB, Neri-Castro $E$, Bénard-Valle $M$, Alagón A and Fry BG (2021) A Clot Twist: Extreme Variation in Coagulotoxicity Mechanisms in Mexican Neotropical Rattlesnake Venoms. Front. Immunol. 12:612846. doi: 10.3389/fimmu.2021.612846

\section{A Clot Twist: Extreme Variation in Coagulotoxicity Mechanisms in Mexican Neotropical Rattlesnake Venoms}

\author{
Lorenzo Seneci ${ }^{1,2}$, Christina N. Zdenek ${ }^{1}$, Abhinandan Chowdhury ${ }^{1,3}$, \\ Caroline F. B. Rodrigues ${ }^{1,4}$, Edgar Neri-Castro ${ }^{5}$, Melisa Bénard-Valle ${ }^{5}$, Alejandro Alagón ${ }^{5}$ \\ and Bryan G. Fry ${ }^{1 *}$ \\ ${ }^{1}$ Venom Evolution Lab, School of Biological Sciences, University of Queensland, St Lucia, QLD, Australia, ${ }^{2}$ Institute of \\ Biology Leiden (IBL), Leiden University, Leiden, Netherlands, ${ }^{3}$ Department of Biochemistry and Microbiology, North South \\ University, Dhaka, Bangladesh, ${ }^{4}$ Laboratório de Herpetologia, Instituto Butantan, São Paulo, Brazil, ${ }^{5}$ Instituto de \\ Biotecnología, Universidad Autónoma de México, Cuernavaca, Mexico
}

Rattlesnakes are a diverse clade of pit vipers (snake family Viperidae, subfamily Crotalinae) that consists of numerous medically significant species. We used validated in vitro assays measuring venom-induced clotting time and strength of any clots formed in human plasma and fibrinogen to assess the coagulotoxic activity of the four medically relevant Mexican rattlesnake species Crotalus culminatus, C. mictlantecuhtli, C. molossus, and C. tzabcan. We report the first evidence of true procoagulant activity by Neotropical rattlesnake venom in Crotalus culminatus. This species presented a strong ontogenetic coagulotoxicity dichotomy: neonates were strongly procoagulant via Factor $X$ activation, whereas adults were pseudo-procoagulant in that they converted fibrinogen into weak, unstable fibrin clots that rapidly broke down, thereby likely contributing to net anticoagulation through fibrinogen depletion. The other species did not activate clotting factors or display an ontogenetic dichotomy, but depleted fibrinogen levels by cleaving fibrinogen either in a destructive (non-clotting) manner or via a pseudo-procoagulant mechanism. We also assessed the neutralization of these venoms by available antivenom and enzyme-inhibitors to provide knowledge for the design of evidence-based treatment strategies for envenomated patients. One of the most frequently used Mexican antivenoms (Bioclon Antivipmyn ${ }^{\circledR}$ ) failed to neutralize the potent procoagulant toxic action of neonate $C$. culminatus venom, highlighting limitations in snakebite treatment for this species. However, the metalloprotease inhibitor Prinomastat substantially thwarted the procoagulant venom activity, while 2,3-dimercapto-1-propanesulfonic acid (DMPS) was much less effective. These results confirm that venom-induced Factor $X$ activation (a procoagulant action) is driven by metalloproteases, while also suggesting Prinomastat as a more promising potential adjunct treatment than DMPS for this species (with the caveat that in vivo studies are necessary to confirm this potential clinical use). Conversely, the serine protease inhibitor 4-(2-aminoethyl)benzenesulfonyl fluoride hydrochloride (AEBSF) inhibited the direct fibrinogen cleaving actions of $C$. mictlantecuhtli venom, thereby revealing that 
the pseudo-procoagulant action is driven by kallikrein-type serine proteases. Thus, this differential ontogenetic variation in coagulotoxicity patterns poses intriguing questions. Our results underscore the need for further research into Mexican rattlesnake venom activity, and also highlights potential limitations of current antivenom treatments.

Keywords: rattlesnakes, venom, Mexico, blood, coagulotoxicity, snakebite

\section{INTRODUCTION}

Snakebite is a major global health crisis, with an estimated total of 94,000-138,000 fatalities and at least 400,000 cases of permanent disabilities per year. These numbers are wellrecognized as gross-underestimates due to poor or non-existent epidemiological record keeping in the most affected regions $(1,2)$. At the root of such dismal statistics is a combination of factors such as rampant poverty, a lack of professional medical assistance in snakebite hotspots-leading to the time-wasting use of ineffective traditional "remedies" - and antivenoms which may be ineffective, inaccessible, or unaffordable (2-7).

Antivenom has long been a neglected or "orphan" drug due to the high costs of production, limited markets, and the fact that it is needed the most by those who can afford it the least $(3,5)$. The market limitations are due to venom being an extremely dynamic trait with extensive variations occurring between distantly related species, regional variations across the range of a widely distributed species, or even variations during the different life-stages of an individual snake. All these factors may dramatically limit the efficacy of an antivenom, thereby restricting the scope of its use $(4,8,9)$.

Of particular concern for antivenom production and efficacy are wide-ranging, taxonomically complex clades such as rattlesnakes (genera Crotalus and Sistrurus), which are responsible for most snakebite envenoming cases in the United States (10-13) and a significant proportion throughout Latin America $(10,14,15)$. Rattlesnakes are a highly diverse clade of pit vipers (Viperidae: Crotalinae) found throughout the Americas from southern Canada to northern Argentina (10). It is therefore unsurprising that they have received considerable research attention, ranking among the most studied snake clade worldwide for decades (16) and serving as model organisms for numerous works in several fields such as biogeography $(17,18)$, evolutionary biology $(19,20)$, and ethology (21). These snakes have adapted to a variety of ecosystems, from tallgrass prairies and deserts, through tropical and temperate forests, which resulted in great phenotypic and ecological diversity within the group $(18,22,23)$.

Mexico harbors the highest diversity of rattlesnake species in the world $(22,24)$. Among the most iconic and medically significant rattlesnake species in Mexico are the Neotropical rattlesnakes: Crotalus culminatus, C. ehecatl, C. mictlantecuhtli, C. simus, and C. tzabcan. These species are part of the Crotalus durissus complex, which also includes the eponymous species C. durissus alongside C. vegrandis $(22,25,26)$ and is in turn included in the C. durissus group with a sister clade comprising C. basiliscus, C. molossus, C. ornatus, and C. totonacus [(22,
27), Figure 1]. These medium- to large-bodied rattlesnakes range from the southwestern United States (C. molossus) to northern Argentina (C. durissus), where they are responsible for a considerable number of serious envenoming cases $(14,15,28-$ 32).

A large body of research has been conducted on venom activity and composition in the $C$. durissus group. The widespread presence of the neurotoxic phospholipase $\mathrm{A}_{2}$ crotoxin in several species (33-37) places most Neotropical rattlesnakes (at least in early life stages) in the Type II venom category described by Mackessy (38). This class includes species possessing highly toxic venoms characterized by systemic neurotoxicity inducing rapid paralysis due to respiratory failure, rather than hemorrhagic symptoms (39-42). Conversely, phenotypes that are dominated by hemorrhagic and tissuedestroying snake venom metalloproteases (SVMPs) and generally devoid of neurotoxins are classified into the Type I category (38), which encompasses low-toxicity venoms inducing mostly cytotoxic and/or hemotoxic symptoms. However, the broad designation into Type I or Type II venoms does not fully account for factors such as ontogeny, prey specificity, intraspecific variation, and coagulotoxicity through differential biochemical pathways, and thus it is not reflective of actual biological diversity, which limits its categorical usefulness.

Neotropical rattlesnake venoms contain multiple toxins that disrupt hemostasis by targeting the blood clotting cascade, the concentration of which is often ontogenetic as well (35, 43-46). Research into coagulotoxicity produced by rattlesnake venoms has been largely focused upon anticoagulant toxins linked to the production of hemorrhagic shock through a combination of platelet inhibition, inhibition of activated clotting enzymes, depletion of fibrinogen levels, and degradation of the basement membrane of blood vessel walls leading to extravascular fluid loss (47-49). Fibrinogen depletion may occur in two ways, either via direct degradation by kallikrein-type serine proteases or metalloproteases, or through a pseudoprocoagulant action by 0005 kallikrein-type serine proteases where fibrinogen is converted to aberrant fibrin strands that form weak, transient clots that rapidly break down (50-54). Pseudoprocoagulant activity is distinguished from true procoagulant activity, i.e., the activation of clotting factors such as Factor $\mathrm{X}$ or prothrombin (55-59), by the nature of the fibrin clot formed. In pseudo-procoagulant venoms the direct action upon fibrinogen produces aberrant clots, while true procoagulant venoms generate endogenous thrombin which in turn produces well-ordered fibrin clots that contribute to the immobilization of prey through induction of stroke. In human victims, either scenario leads to venom-induced consumption coagulopathy 


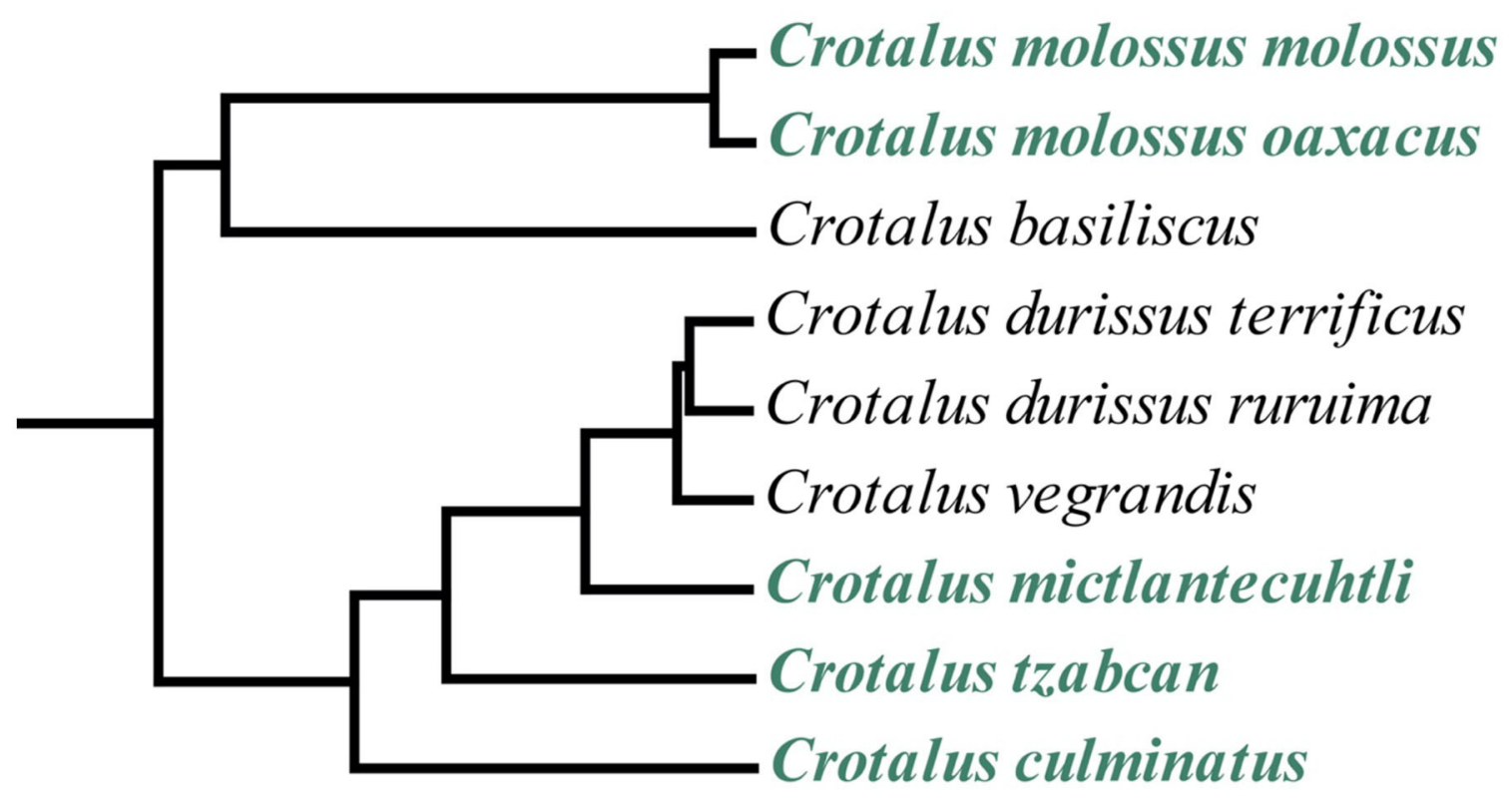

FIGURE 1 | Phylogenetic tree of the Crotalus durissus group from a parallel study (timetree.org) showing the relationships between the C. durissus complex (Neotropical rattlesnakes) and the C. molossus complex. Species analyzed in this study are shown in green. Not all members of the clade are represented in the tree.

(VICC), with extensive internal and external hemorrhage. Both SVMPs and snake venom serine proteases (SVSPs) are virtually ubiquitous across the rattlesnake clade, including Neotropical rattlesnakes (38).

In contrast to the well-documented anticoagulant effects, reports of true procoagulant activity in rattlesnake venom are scant and often inconclusive $(60,61)$, with the notable exception of $C$. helleri $(62,63)$. However, the paucity of data supporting the presence of true procoagulant toxins might have been influenced by intrinsic limitations in standard coagulotoxicity assays such as the procedure devised by Reid and Theakston (64), whereby $\mathrm{Ca}^{2+}$ and phospholipids are not added to citrated plasma prior to incubation with venom. As citration inactivates the clotting cascade by chelating ionized $\mathrm{Ca}^{2+}$, it is essential to add $\mathrm{Ca}^{2+}$ back in to reproduce physiological conditions. Furthermore, since plasma alone lacks both activated platelets and activated/apoptotic endothelial cells (i.e., the physiological source of phospholipids), its phospholipid concentration is likely low (65). Therefore, while trace amounts of phospholipids are present in citrated plasma, such small concentrations are not reflective of normal physiological conditions and would be rapidly depleted. Many studies have indeed clearly documented that both cofactors significantly affect relative coagulotoxicity $(50-53,56-59,66-76)$. However, despite this critical importance having been known for decades, assay designs in many snake venom coagulotoxicity studies have included $\mathrm{Ca}^{2+}$ but not phospholipids (77-93) or neither of the clotting cofactors $(32,94-104)$. This may dramatically skew the results, to the point that procoagulant activity might be missed entirely for venoms that are inactive in the absence of clotting cofactors or generate enzymes such as FXa which are themselves obligately dependent upon $\mathrm{Ca}^{2+}$ for activity.

Since in vitro coagulotoxicity assays for the Mexican members of the $C$. durissus complex have largely followed methodologies that did not reproduce physiological conditions $(32,44)$, true procoagulant venom phenotypes could have gone undiscovered in this lineage. This could hamper antivenom efficacy and symptomatic treatment alike, as both anticoagulant and procoagulant venoms result in a net anticoagulant effect in human victims and thus cannot be distinguished on the basis of symptomatology. Therefore, in this study we investigated the clinical implications and possible evolutionary characteristics of coagulotoxicity in four species of the $C$. durissus group from Mexico, with a particular focus upon elucidating the type of coagulotoxicity (i.e., anticoagulant, pseudo-procoagulant, or true procoagulant) caused by the venoms. We assessed venom-induced clotting times and clot strength on human plasma and fibrinogen, ensuring to include $\mathrm{Ca}^{2+}$ and phospholipids in the assays to replicate physiological conditions, and testing clotting factor dependency under controlled conditions. We also tested the neutralization of these venoms by Bioclon Antivipmyn ${ }^{\circledR}$, one of the main antivenoms marketed in Mexico, which is produced using Bothrops asper and Crotalus simus venom. We then repeated the tests using the commercially available metalloprotease inhibitors 2,3-dimercapto-1-propanesulfonic acid (DMPS) and Prinomastat, which have been shown to neutralize SVMPs in other venomous snake species $(105,106)$. Our findings provide valuable information for clinicians and antivenom producers 
regarding effective diagnosis and treatment of Neotropical rattlesnake envenoming in Mexico.

\section{MATERIALS AND METHODS}

\section{Venom Selection and Preparation}

All venom work was performed under University of Queensland Approval \#IBC134BSBS2015. Our study included 25 venom samples from C. culminatus $(n=15)$, C. mictlantecuhtli $(n=2)$, and C. tzabcan $(n=9)$, from the venom bank of the laboratory at IBt, UNAM (Herpetario Cantil). The C. mictlantecuhtli samples were obtained from pooling the venoms of juvenile $(n=5)$ and adult $(n=7)$ individuals. Table 2 details the age category and locality of origin of each snake. Three venom samples from $C$. molossus (1 C. m. molossus and 2 C. m. oaxacus) were taken from the Venom Evolution Lab long-term cryogenic collection. One $\mathrm{mg}$ of each venom was transferred into a $1.5 \mathrm{~mL}$ Eppendorf tube under sterile conditions. Subsequently, $\mathrm{ddH}_{2} \mathrm{O}$ (doubledistilled water) was added to the sample before vortexing for $5 \mathrm{~s}$ and centrifuging $\left(4^{\circ} \mathrm{C}, 14,000 \mathrm{RCF} ; 10 \mathrm{~min}\right)$. The supernatant was then transferred to another $1.5 \mathrm{~mL}$ Eppendorf tube and the protein concentration determined in triplicate vortexing between replicates on a Nanodrop 2000 spectrophotometer at $280 \mathrm{~nm}$ (ThermoFisher Scientific). The resulting concentration values were used to obtain a final working stock of $1 \mathrm{mg} / \mathrm{mL}$ in $50 \%$ glycerol to prevent freezing at $-20^{\circ} \mathrm{C}$. Lastly, the samples were vortexed and aliquoted into $200 \mu \mathrm{L}$ Eppendorf tubes for storage at $-80^{\circ} \mathrm{C}$ until use. All venom samples were kept on ice throughout the process to avoid degradation.

\section{Plasma and Fibrinogen Coagulation Assays}

All human plasma work was performed under University of Queensland Biosafety Approval \#IBC134BSBS2015 and Human Ethics Approval \#2016000256. Healthy human plasma (3.2\%, citrated Lots\# A540020142331 and \# A5400201137021, which were pooled together) was provided by the Australian Red Cross (44 Musk Street, Kelvin Grove, Queensland 4059). Plasma stocks were aliquoted into $1.5 \mathrm{~mL}$ Eppendorf tubes under sterile conditions before flash-freezing in liquid nitrogen and stored at $-80^{\circ} \mathrm{C}$ until use. Human fibrinogen was purchased from Sigma Aldrich (St. Louis, Missouri, United States, catalog \#F3879) and aliquoted into $1.5 \mathrm{~mL}$ Eppendorf tubes after reconstitution into a

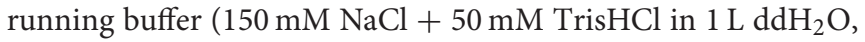
$\mathrm{pH} 7.4$ ) to a concentration of $4 \mathrm{mg} / \mathrm{mL}$. The aliquots were flashfrozen in liquid nitrogen for $10 \mathrm{~s}$ and stored at $-80^{\circ} \mathrm{C}$ until use.

Plasma and fibrinogen clotting times were measured on a Stago STA-R Max coagulation analyzer (Stago, Asniéres sur Seine, France) which determines clotting time via the time required for an oscillating magnetic ball inside a cuvette containing 250 $\mu \mathrm{L}$ solution to cease moving due to blockage caused by a clot. A detailed overview of the assays we performed is provided in Table 1. Prior to experimentation, a positive control for plasma was performed via an activated Partial Thromboplastin Time (aPTT) test as described by Lister et al. (107). A custom positive control assay was devised for fibrinogen whereby $50 \mu \mathrm{L} 50 \%$ $\mathrm{ddH}_{2} \mathrm{O}$ :glycerol, $25 \mu \mathrm{L}$ of a 2:1 dilution of $\mathrm{CaCl}_{2}+\mathrm{OK}$ buffer, 50
TABLE 1 | Overview of coagulation assays performed on STA-R Max hemostasis analyzer.

\begin{tabular}{|c|c|}
\hline Assay & Methodology \\
\hline \multirow[t]{2}{*}{$\begin{array}{l}\text { Venom-induced } \\
\text { clotting time }\end{array}$} & $\begin{array}{l}\text { Step 1: } 50 \mu \mathrm{L} \text { venom }(100 \mu \mathrm{g} / \mathrm{mL})+50 \mu \mathrm{L} 0.025 \mathrm{M} \text { calcium } \\
\text { (Stago catalog \#00367) }+25 \mu \mathrm{L} \text { Owren-Koller (OK) buffer } \\
\text { (Stago catalog \#00360) }+50 \mu \mathrm{L} \text { phospholipids (Stago kit; } \\
\text { catalog \#00597) }\end{array}$ \\
\hline & $\begin{array}{l}\text { Step 2: } 120 \mathrm{~s} \text { incubation at } 37^{\circ} \mathrm{C}+75 \mu \mathrm{L} \text { human } \\
\text { plasma/human fibrinogen }\end{array}$ \\
\hline \multirow[t]{2}{*}{$\begin{array}{l}\text { Calcium } \\
\text { dependence }\end{array}$} & $\begin{array}{l}\text { Step 1: } 50 \mu \mathrm{L} \text { venom }(100 \mu \mathrm{g} / \mathrm{mL})+75 \mu \mathrm{L} \text { OK buffer }+50 \mu \mathrm{L} \\
\text { phospholipids }\end{array}$ \\
\hline & $\begin{array}{l}\text { Step 2: } 120 \mathrm{~s} \text { incubation at } 37^{\circ} \mathrm{C}+75 \mu \mathrm{L} \text { human } \\
\text { plasma/human fibrinogen }\end{array}$ \\
\hline \multirow[t]{2}{*}{$\begin{array}{l}\text { Phospholipids } \\
\text { dependence }\end{array}$} & $\begin{array}{l}\text { Step 1: } 50 \mu \mathrm{L} \text { venom }(100 \mu \mathrm{g} / \mathrm{mL})+50 \mu \mathrm{L} 0.025 \mathrm{M} \text { calcium }+ \\
75 \mu \mathrm{L} \text { OK buffer }\end{array}$ \\
\hline & $\begin{array}{l}\text { Step 2: } 120 \mathrm{~s} \text { incubation at } 37^{\circ} \mathrm{C}+75 \mu \mathrm{L} \text { human } \\
\text { plasma/human fibrinogen }\end{array}$ \\
\hline \multirow[t]{2}{*}{ Antivenom } & $\begin{array}{l}\text { Step 1: } 50 \mu \mathrm{L} \text { venom }(100 \mu \mathrm{g} / \mathrm{mL})+50 \mu \mathrm{L} 0.025 \mathrm{M} \text { calcium }+ \\
25 \mu \mathrm{L} 2.5 \% \text { antivenom }+50 \mu \mathrm{L} \text { phospholipids }\end{array}$ \\
\hline & $\begin{array}{l}\text { Step 2: } 120 \mathrm{~s} \text { incubation at } 37^{\circ} \mathrm{C}+75 \mu \mathrm{L} \text { human } \\
\text { plasma/human fibrinogen }\end{array}$ \\
\hline \multirow[t]{2}{*}{ Prinomastat } & $\begin{array}{l}\text { Step 1: } 50 \mu \mathrm{L} \text { venom }(100 \mu \mathrm{g} / \mathrm{mL})+50 \mu \mathrm{L} 0.025 \mathrm{M} \text { calcium }+ \\
25 \mu \mathrm{L} 2 \mathrm{mM} \text { Prinomastat (Sigma-Aldrich, PZ0198-5MG) }+50 \\
\mu \mathrm{L} \text { phospholipids }\end{array}$ \\
\hline & Step 2: $120 \mathrm{~s}$ incubation at $37^{\circ} \mathrm{C}+75 \mu \mathrm{L}$ human plasma \\
\hline \multirow[t]{2}{*}{ DMPS } & $\begin{array}{l}\text { Step 1: } 50 \mu \mathrm{L} \text { venom }(100 \mu \mathrm{g} / \mathrm{mL})+50 \mu \mathrm{L} 0.025 \mathrm{M} \text { calcium }+ \\
25 \mu \mathrm{L} 2 \mathrm{mM} / 20 \mathrm{mM} \text { DMPS (ThermoFisher, U138044) }+50 \mu \mathrm{L} \\
\text { phospholipids }\end{array}$ \\
\hline & $\begin{array}{l}\text { Step 2: } 120 \mathrm{~s} / 20 \mathrm{~min} \text { incubation at } 37^{\circ} \mathrm{C}+75 \mu \mathrm{L} \text { human } \\
\text { plasma }\end{array}$ \\
\hline AEBSF & $\begin{array}{l}\text { Step 1: } 50 \mu \mathrm{L} \text { venom }(100 \mu \mathrm{g} / \mathrm{mL})+50 \mu \mathrm{L} 0.025 \mathrm{M} \text { calcium + } \\
25 \mu \mathrm{L} 2 \mathrm{mM} \text { AEBSF (Sigma-Aldrich, A8456-25MG) }+50 \mu \mathrm{L} \\
\text { phospholipids }\end{array}$ \\
\hline
\end{tabular}

$\mu \mathrm{L}$ phospholipids, and $75 \mu \mathrm{L}$ human fibrinogen were incubated for $120 \mathrm{~s}$ before adding $50 \mu \mathrm{L}$ thrombin (STA Liquid-FIB, Stago catalog \# 00673) for a total volume of $250 \mu \mathrm{L}$. Negative controls for both plasma and fibrinogen were run by replacing the venom

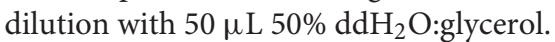

$3.2 \%$ citrated plasma from cane toad (Rhinella marina) was aliquoted into $800 \mu \mathrm{L}$ quantities, which were flash-frozen in liquid nitrogen, and stored at $-80^{\circ} \mathrm{C}$. This plasma was obtained under University of Queensland Animal Ethics Committee approval SBS/020/15/ARC.

\section{Cofactor Dependence Assays}

To test whether the (pseudo)procoagulant action of venoms requires specific cofactors, dependence tests were performed using the plasma protocols from 2.2 on six representative Neotropical rattlesnake venoms (fastest- and slowest-clotting samples on plasma per species, with the exception of secondslowest adult C. culminatus) whereby the samples were incubated with human plasma and fibrinogen in the absence of either $\mathrm{Ca}^{2+}$ or phospholipids. Additional tests were conducted in a nonplasma assay which allowed for the strict control of either cofactor (see section Blood Clotting Factor Activation Assay below). 


\section{Antivenom Neutralization and Inhibition Assays}

One bottle of lyophilized Antivipmyn ${ }^{\circledR}$ antivenom serum [Instituto Bioclon, Calz. de Tlalpan 4691, Mexico City, Mexico; batch: B-6F-16, expiry date October 2010 and protein concentration of $13.7 \mathrm{mg} F\left(\mathrm{ab}^{\prime}\right)_{2} / \mathrm{mL}$ ] was diluted in $10 \mathrm{~mL}$ $\mathrm{ddH}_{2} \mathrm{O}$ and centrifuged $\left(3,900 \mathrm{RCF}, 4^{\circ} \mathrm{C}, 10 \mathrm{~min}\right)$ to remove any potential particulates. Expired antivenoms were not a concern, as antivenoms have been shown to be stable over time, with powdered antivenoms shown to be particularly resilient but even liquid antivenoms have been shown to be active for at least 60 years (107-109). Subsequently, the antivenom mixture was filtered $(0.45 \mu \mathrm{m})$ and aliquoted into $2 \mathrm{~mL}$ Eppendorf tubes in sterile conditions, then stored at $+4^{\circ} \mathrm{C}$ until use. For testing in STAR-Max, the antivenom was diluted in $\mathrm{OK}$ buffer to a $2.5 \%$ concentration, as determined to be effective during preliminary testing against C. mictlantecuhtli (formerly C. simus from Veracruz, Mexico) due to the presence of venom from this species in the immunizing mixture. Eightpoint dilution curves were run for six venoms incubated at eight different concentrations ( $\mu \mathrm{g} / \mathrm{mL}: 20,10,4,1.66,0.66,0.25,0.125$, and 0.05).

To test for inhibition of venom metalloprotease activity on plasma, eight-point curves were run on two representative venoms whereby the metalloprotease inhibitors Prinomastat hydrochloride (catalog \#PZ0198, Sigma Aldrich, St. Louis, Missouri, US) and 2,3-dimercapto-1-propanesulfonic acid (DMPS, catalog \#D8016 Sigma Aldrich, St. Louis, Missouri, US) replaced OK buffer as reagents in separate assays. Prinomastat was solubilized in DMSO, diluted to a $10 \mathrm{mM}$ concentration using $\mathrm{ddH}_{2} \mathrm{O}$, and subsequently stored at $-80^{\circ} \mathrm{C}$ until use in STA-R Max. For this step, the inhibitor aliquots were thawed and pooled to a $900 \mu \mathrm{L}$ total volume diluted into 3,600 $\mu \mathrm{L}$ OK buffer to dilute the concentration to $2 \mathrm{mM}$. DMPS was solubilized in DMSO and diluted in $\mathrm{ddH}_{2} \mathrm{O}$ to a $20 \mathrm{mM}$ concentration before storage at $-80^{\circ} \mathrm{C}$. Prinomastat and DMPS aliquots were covered in aluminum foil to prevent exposure to light and degradation. Antivenom and inhibitor testing were performed using pooled plasma batch \# A540020103540). We repeated the original baseline values for all species to demonstrate congruence and the plotting of dilution curves for the species upon which antivenom and inhibitors were tested.

Inhibition of serine protease activity on fibrinogen in a representative venom was assessed by running an eight-point curve with the serine protease inhibitor 4-(2aminoethyl)benzenesulfonyl fluoride hydrochloride (AEBSF, catalog \#A8456, Sigma Aldrich, St. Louis, Missouri, US) as a reagent in place of OK buffer. AEBSF was diluted with $\mathrm{ddH}_{2} \mathrm{O}$ into $20 \mathrm{mM}$ aliquots which were covered in aluminum foil and stored at $-80^{\circ} \mathrm{C}$ until use. For testing in STA-R Max, a $20 \mathrm{~min}$ incubation step with AEBSF was included before addition of fibrinogen as per (52).

\section{Thromboelastography}

To assess the strength of venom-induced clots in plasma and fibrinogen, thromboelastography was performed on nine representative venoms using a Thromboelastogram ${ }^{\circledR}$ 5000 Hemostasis analyzer (Haemonetics ${ }^{\circledR}$, Haemonetics Australia Pty Ltd., North Rdye, Sydney, Australia). The same ratio of reagents for STA-R Max assays was maintained for thromboestography. Briefly, $189 \mu \mathrm{L}$ plasma (Label \# A540020142331/A5400201137021) or fibrinogen (\#Lot SLCC4502, \#Lot SLBZ2294) were added to $72 \mu \mathrm{L} \mathrm{CaCl}_{2}(25 \mathrm{mM}$ solution), $72 \mu \mathrm{L}$ phospholipids diluted in OK buffer, $20 \mu \mathrm{L} \mathrm{OK}$ buffer, and $7 \mu \mathrm{L}$ venom $(1 \mathrm{mg} / \mathrm{mL})$. Thromboelastography for $C$. molossus ssp. samples was performed using pooled plasma batch \# A540020103540 due to degradation of the original plasma stock during a COVID-19 lockdown period, with the repeating of the original baseline values to demonstrate congruence. For plasma, a spontaneous (i.e., negative) clotting control was run with $50 \% \mathrm{ddH}_{2} \mathrm{O}$ :glycerol in place of the venom, whereas $7 \mu \mathrm{L}$ thrombin (STA Liquid FIB, Stago) or $7 \mu \mathrm{L}$ bovine Factor Xa (Liquid Anti-Xa FXa, Stago) were used to run two independent positive controls. Only thrombin was used as a positive control for fibrinogen. Thromboelastography data were visualized on Adobe Photoshop.

\section{Blood Clotting Factor Activation Assay}

Venom-induced activation of coagulation Factor II (prothrombin) and Factor $\mathrm{X}$ (FX) for nine representative venoms was investigated using a Fluoroskan ${ }^{\mathrm{TM}}$ microplate fluorometer (ThermoFisher Scientific, 168 Third Avenue, Waltham, MA 02451, USA). This machine measures activation of clotting factors by monitoring cleavage of a specific substrate (and corresponding fluorescence emitted) by an activated enzyme. The following reagents were manually pipetted into each experimental well in 384-well plates: $10 \mu \mathrm{L}$ phospholipids (STA CK Prest, Stago), $10 \mu \mathrm{L}$ venom, $10 \mu \mathrm{L}$ zymogen. To determine the activity of the venom directly on the substrate, the zymogen was replaced with $10 \mu \mathrm{L}$ Fluoroskan running buffer without $\mathrm{Ca}^{2+}(150 \mathrm{mM} \mathrm{NaCl}+50 \mathrm{mM}$ Tris, $\mathrm{pH}$ 7.4) in venom control wells. Activated factors replaced zymogens in positive control wells. A blank control without zymogen or venom was also included. ES011 substrate (Boc-Val-Pro-Arg-AMC. Boc: t-Butyloxycarbonyl; 7-Amino-4- methyl coumarin) was diluted to a $2 \mu \mathrm{g} / \mathrm{mL}$ concentration in Fluoroskan running buffer with

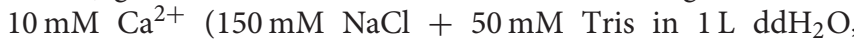
$+10 \mathrm{mM} \mathrm{Ca}^{2+}, \mathrm{pH}$ 7.4). Seventy microliters of the dilution were then dispensed into each well by the machine to enable factor activation. All zymogens were diluted in Fluoroskan running buffer without $\mathrm{Ca}^{2+}$ to a $10 \mu \mathrm{g} / \mathrm{mL}$ concentration. Venom concentration was $1 \mu \mathrm{g} / \mathrm{mL}$ in running buffer without $\mathrm{Ca}^{2+}$ for FX activation. The prothrombin assay required the venom and zymogen concentrations to be lowered to 0.1 and $1 \mu \mathrm{g} / \mathrm{mL}$, respectively, for subsequent analysis purposes due to the otherwise excessively high activity of the thrombin control. Activation was measured as the percentage of activated factor for each venom compared to the positive control (i.e., active enzyme wells), which represented the $100 \%$ activation benchmark. To test for cofactor dependence in FX activation, the assay was repeated by incubating venom with both cofactors vs. without phospholipids vs. without $\mathrm{Ca}^{2+}$. 


\section{D Polyacrylamide Gel Electrophoresis (SDS-PAGE)}

Non-reduced 1D 12\% SDS-PAGE was run in triplicate to assess the activity of selected venoms on prothrombin. Venom $(0.2$ $\mu \mathrm{g}$ ) was reconstituted in $\mathrm{ddH}_{2} \mathrm{O}$ and incubated at $37^{\circ} \mathrm{C}$ for $10 \mathrm{~min}$ with $2 \mu \mathrm{g}$ prothrombin in a total volume of $7.5 \mu \mathrm{L}$. Negative (venom only; prothrombin only) and positive controls (thrombin only) were included in each gel. Then, $7.5 \mu \mathrm{L}$ 2x laemmli dye (Bio-Rad Hercules, CA, USA) was added to each sample, resulting in a final volume of $15 \mu \mathrm{L}$. Lastly, the samples were stored at $-20^{\circ} \mathrm{C}$ until use. Thirty milliliter of

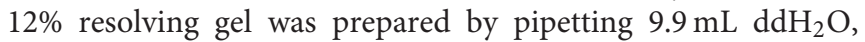
$12.0 \mathrm{~mL} 30 \%$ Acrylamide mix (Bio-Rad, Hercules, CA, USA), 7.5 mL 1.5 Tris-glycine $\mathrm{pH} 8.8$ (Tris- Sigma Aldrich, St. Louis, MO, USA; glycine- Sigma Aldrich, St. Louis, MO, USA), 300 $\mu \mathrm{L}$ 10\% SDS (SDS- Sigma-Aldrich, St. Louis, MO, USA), 300 $\mu \mathrm{L}$ 10\% Ammoniun persulfate (APS- Bio-Rad, Hercules, CA, USA), and $18 \mu \mathrm{L}$ TEMED in a $50 \mathrm{~mL}$ falcon tube. Six milliliter

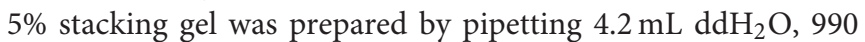
$\mu \mathrm{L} 30 \%$ Acrylamide mix (Bio-Rad, Hercules, CA, USA), 750 $\mu \mathrm{L}$ 0.5 M Tris-glycine pH 6.8 (Tris- Sigma Aldrich, St. Louis, MO, USA; glycine- Sigma Aldrich, St. Louis, MO, USA), 60 $\mu \mathrm{L}$ 10\% SDS (SDS- Sigma-Aldrich, St. Louis, MO, USA), 60 $\mu \mathrm{L} 10 \%$ APS (APS- Bio-Rad, Hercules, CA, USA), and $6 \mu \mathrm{L}$ TEMED in a $15 \mathrm{~mL}$ falcon tube. Both gels were rested for $15 \mathrm{~min}$ to allow for polymerization before allocation into a Mini-PROTEAN Tetra Vertical Electrophoresis Cell (Bio-Rad, Hercules, CA, USA). 10x running buffer was prepared using the following recipe: $30 \mathrm{~g}$ Tris (Sigma Aldrich, St. Louis, MO, USA) + 144 g glycine (Sigma Aldrich, St. Louis, MO, USA) $+20 \mathrm{~g}$ SDS (Sigma Aldrich, St. Louis, MO, USA) diluted

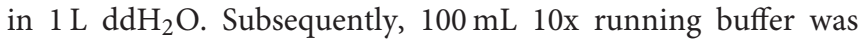

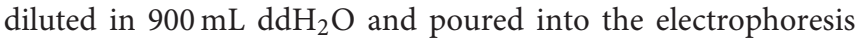
chamber before manual loading of samples into the wells. A Dual Color protein standard (Bio-Rad, Hercules, CA, USA, range $=10-250 \mathrm{kD}$ ) was used as a ladder for molecular weight reference. Gels were run for $2.5 \mathrm{~h}$ at $120 \mathrm{~V}$, then stained overnight with $1 \mathrm{~g} / \mathrm{L}$ Coomassie colloidal brilliant blue G250 [34\% methanol (VWR Chemicals, Tingalpa, QLD, Australia), 3\% orthophosphoric acid (Merck, Darmstadt, Germany), $170 \mathrm{~g} / \mathrm{L}$ ammonium sulfate (Bio-Rad, Hercules, CA, USA)] followed by destaining in $\mathrm{ddH}_{2} \mathrm{O}$.

\section{Statistics}

All tests were performed in quadruplicate $(n=4)$ bar the antivenom and inhibitor efficacy curves, which were run in triplicate $(n=3)$. Statistical analyses and graphing were performed in GraphPad PRISM v. 8.4.2. Cofactor dependence results were analyzed using repeated measures ANOVA via Dunnett's multiple comparisons test. This method allows for comparisons of each treatment (in our case, $\mathrm{Ca}^{2+}$-devoid and phospholipids-devoid conditions) to a control (normal conditions with both cofactors present). A repeated-measures approach was chosen because all clotting tests (i.e., control vs. treatment conditions) were conducted on the same venom sample for each species. Correlation tests were performed using Spearman's rank-order correlation due to age being coded as an ordinal variable with four categories $(1=$ neonate, 2 = juvenile, 3 = young adult, 4 = adult). Normality was determined with four different tests (ShapiroWilk, Kolmogorov-Smirnov, Anderson-Darling, D’Agostino and Pearson) but only the Shapiro-Wilk results were used since $n$ $=4$ was too small for the other tests. Significance was set at $p=0.05$.

\section{RESULTS}

\section{Coagulotoxicity Assay}

The venoms of neonate C. culminatus were strongly procoagulant, whereas adults appeared to have largely lost this trait (Table 2). Age of the animal and venom-induced clotting time were significantly correlated in C. culminatus for plasma $(r=0.8506, p<0.0001)$ and fibrinogen $(r=$ 0.7423, $p<0.0001$ ). Both juvenile and adult $C$. mictlantecuhtli pools displayed short clotting times on plasma and especially fibrinogen, whereas greater individual variation was observed in C. tzabcan (Table 2).

The cofactor dependence results confirm that coagulotoxins in the venom of these rattlesnakes are strongly dependent on cofactors, particularly $\mathrm{Ca}^{2+}$ (Tables 3, 4). Repeatedmeasures ANOVA yielded highly significant results regarding calcium dependence for all venoms on plasma, which was however markedly less pronounced for fibrinogen. Absence of phospholipids was not significant for one C. tzabcan sample and either C. mictlantecuhtli representatives (Table 3). Interestingly, all venoms clotted fibrinogen significantly faster in the absence of phospholipids than in normal conditions (Table 4). Relative co-factor dependence tests for zymogen activation by $C$. culminatus neonate were further investigated using completely controlled conditions in a non-plasma-based assay to eliminate the background fibrinogen-clotting effect (see section Blood Clotting Factor Activation Assay below).

\section{Venom Neutralization by Antivenom and Inhibitors}

Eight-point dilution curves of antivenom efficacy indicate that Antivipmyn ${ }^{\circledR}$ effectively counteracts the pseudo-procoagulant action of neonate C. culminatus, C. tzabcan (Solidaridad), and both $C$. mictlantecuhtli pools, with a noticeable spike in antivenom efficacy from a $1.66 \mu \mathrm{g} / \mathrm{mL}$ venom dilution onwards (Figure 2). Venoms from adult C. culminatus and C. tzabcan (Oxkutzcab) only weakly affected fibrinogen compared to the other four samples, facilitating nearly complete neutralization of pseudo-procoagulant activity by the antivenom. C. mictlantecuhtli venom was also markedly neutralized by the serine protease inhibitor AEBSF (148 $\pm 5.62 \mathrm{~s}, n=3$, figure not shown).

No detectable effect of Antivipmyn ${ }^{\circledR}$ was observed against neonate C. culminatus venom activity on plasma, and only marginal neutralization occurred against venom from an adult of the same species (Figure 2). Neonate C. culminatus venominduced plasma clotting was instead greatly delayed by the metalloprotease inhibitor Prinomastat (particularly at low venom 
TABLE 2 | Clotting times of human plasma and fibrinogen incubated with venoms from C. culminatus, C. mictlantecuhtli, and C. tzabcan specimens.

\begin{tabular}{|c|c|c|c|c|}
\hline Species & Age & Locality & $\begin{array}{l}\text { Mean clotting time } \\
\text { (s) } \pm \text { SD (plasma) }\end{array}$ & $\begin{array}{l}\text { Mean clotting time } \\
\text { (s) } \pm \text { SD (fibrinogen) }\end{array}$ \\
\hline C. culminatus & Neonate & Tlaltizapán, Morelos & $11.625 \pm 0.33$ & $31.775 \pm 0.45$ \\
\hline C. culminatus & Neonate & Yautepec, Morelos & $14.975 \pm 0.20$ & $59.25 \pm 3.10$ \\
\hline C. culminatus & Neonate & Puente de Ixtla, Morelos & $15.175 \pm 0.35$ & $51.3 \pm 4.95$ \\
\hline C. culminatus & Neonate & Iguala, Guerrero & $40.25 \pm 0.19$ & $58.1 \pm 1.84$ \\
\hline C. culminatus & Juvenile & Coahuayana, Michoacán & $14.4 \pm 0.21$ & $190.3 \pm 14.57$ \\
\hline C. culminatus & Juvenile & Coahuayana, Michoacán & $16.925 \pm 0.20$ & $233.3 \pm 3.81$ \\
\hline C. culminatus & Juvenile & Morelos & $18.075 \pm 0.41$ & $30.35 \pm 1.03$ \\
\hline C. culminatus & Juvenile & Morelos & $85.525 \pm 2.13$ & $106.625 \pm 0.45$ \\
\hline C. culminatus & Juvenile & Barranca Honda, Morelos & $107.65 \pm 8.68$ & $144.9 \pm 2.95$ \\
\hline C. culminatus & Young adult & Coahuayana, Michoacán & $19.6 \pm 0.33$ & $108.775 \pm 1.46$ \\
\hline C. culminatus & Young adult & Puebla, Puebla & $90 \pm 1.78$ & $128.5 \pm 0.93$ \\
\hline C. culminatus & Adult & Barranca Honda, Morelos & $120.175 \pm 6.09$ & $192.075 \pm 1.53$ \\
\hline C. culminatus & Adult & Tlaltizapán, Morelos & $122.725 \pm 4.27$ & $189.575 \pm 6.02$ \\
\hline C. culminatus & Adult & Barranca Honda, Morelos & $181.175 \pm 7.99$ & $260.825 \pm 20.39$ \\
\hline C. culminatus & Adult & Cruz Pintada, Tlaltitenango, Morelos & $218.75 \pm 0.73$ & $801.675 \pm 65.32$ \\
\hline C. mictlantecuhtli & Juvenile (pool $N=6)$ & Veracruz & $46.275 \pm 1.11$ & $37.1 \pm 0.46$ \\
\hline C. mictlantecuhtli & Adult (poo $N=6 l)$ & Veracruz & $48.825 \pm 0.52$ & $41.775 \pm 1.30$ \\
\hline C. tzabcan & Neonate & Dzibilchatún, Yucatán & $161.3 \pm 4.65$ & $149.65 \pm 9.26$ \\
\hline C. tzabcan & Juvenile & Calakmul, Campeche & $79.425 \pm 1.26$ & $77.975 \pm 2.24$ \\
\hline C. tzabcan & Juvenile & Mérida, Yucatán & $242 \pm 57.00$ & $265.6 \pm 21.35$ \\
\hline C. tzabcan & Juvenile & Chetumal, Quintana Roo & $230.525 \pm 1.80$ & $325.45 \pm 4.95$ \\
\hline C. tzabcan & Adult & Solidaridad, Quintana Roo & $73.225 \pm 2.53$ & $83.675 \pm 4.01$ \\
\hline C. tzabcan & Adult & Chetuma, Quintana Roo & $112.975 \pm 2.17$ & $109.875 \pm 6.95$ \\
\hline C. tzabcan & Adult & Mérida, Yucatán & $211.525 \pm 7.31$ & $223.875 \pm 5.39$ \\
\hline C. tzabcan & Adult & Oxkutzcab, Yucatán & $267.55 \pm 1.75$ & $902.175 \pm 119.35$ \\
\hline
\end{tabular}

Plasma spontaneous control $=607 \pm 23.39$ s. Fibrinogen spontaneous control $=999 \mathrm{~s}$.

TABLE 3 | Cofactor dependence tests for six representative venoms (C. culminatus, C. tzabcan, and C. mictlantecuhtli) incubated with human plasma.

\begin{tabular}{|c|c|c|c|c|}
\hline Species & Locality & Normal & $\begin{array}{l}\text { Phospholipid dependence } \\
\text { (no phospholipids) }\end{array}$ & $\begin{array}{c}\mathrm{Ca}^{2+} \text { dependence } \\
\left(\text { no } \mathrm{Ca}^{2+}\right)\end{array}$ \\
\hline C. culminatus neonate & Tlaltizapán, Morelos & $11.63 \pm 0.33$ & $22.10 \pm 0.46^{\star \star \star}$ & $54.975 \pm 0.80^{\star \star \star}$ \\
\hline C. culminatus adult & Barranca Honda, Morelos & $181.20 \pm 7.99$ & $178.62 \pm 4.77$ & $404.32 \pm 17.65^{\star \star}$ \\
\hline C. tzabcan adult & Solidaridad, Quintana Roo & $73.23 \pm 2.53$ & $96.35 \pm 3.16^{\star \star \star}$ & $164.77 \pm 2.62^{\star \star \star}$ \\
\hline C. tzabcan adult & Oxkutzcab, Yucatán & $267.6 \pm 1.75$ & $333.47 \pm 21.88^{*}$ & $999 \pm 0^{\star \star \star}$ \\
\hline C. mictlantecuhtli juvenile (pool) & Veracruz & $46.29 \pm 1.14$ & $48.025 \pm 3.36$ & $79.325 \pm 0.80^{\star \star \star}$ \\
\hline C. mictlantecuhtli adult (pool) & Veracruz & $48.83 \pm 0.52$ & $53.8 \pm 3.84$ & $84.95 \pm 1.25^{\star \star \star}$ \\
\hline
\end{tabular}

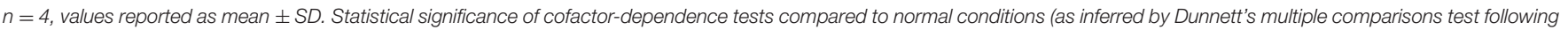
repeated-measures ANOVA) shown as follows: ${ }^{\star} p<0.05,{ }^{* *} p<0.001,{ }^{* \star *} p<0.0001$. All values represent venom-induced clotting times (s).

concentrations), whereas the adult individual was affected to a lesser degree. DMPS failed to neutralize either neonate or adult C. culminatus venom using the same assay as with Prinomastat (Figure 3). Furthermore, DMPS showed anticoagulant effects on plasma even in the absence of venom. Importantly, a different adult C. culminatus venom was used for antivenom + inhibitor tests and factor activation analysis (section Blood Clotting Factor Activation Assay) than the one used for clotting time assays and thromboelastography due to running out of the original stock. However, the results were congruent between the two venoms samples, which was consistent with both being from adult snakes from the same region.

\section{Thromboelastography}

Thromboelastography was conducted on plasma and fibrinogen as follows: Figure 4 shows the human plasma thromboelastography traces for C. culminatus, C. mictlantecuhtli, and C. tzabcan. Figure 5 shows the human plasma thromboelastography traces for the three $C$. molossus localities; Figure 6 shows the human fibrinogen 
TABLE 4 | Cofactor dependence tests for six representative venoms (C. culminatus, C. tzabcan, and C. mictlantecuhtli) incubated with human fibrinogen.

\begin{tabular}{|c|c|c|c|c|}
\hline Species & Locality & Normal & $\begin{array}{l}\text { Phospholipid dependence } \\
\text { (no phospholipids) }\end{array}$ & $\begin{array}{c}\mathrm{Ca}^{2+} \text { dependence } \\
\left(\text { no } \mathrm{Ca}^{2+}\right)\end{array}$ \\
\hline C. culminatus neonate & Tlaltizapán, Morelos & $33.75 \pm 1.70$ & $27.85 \pm 0.17^{*}$ & $45.65 \pm 0.34^{*}$ \\
\hline C. culminatus adult & Barranca Honda, Morelos & $324.95 \pm 15.73$ & $190.20 \pm 13.76^{\star}$ & $764.60 \pm 72.74^{\star}$ \\
\hline C. tzabcan adult & Solidaridad, Quintana Roo & $76.05 \pm 2.88$ & $39.43 \pm 0.94^{*}$ & $120.50 \pm 2.31^{\star \star}$ \\
\hline C. tzabcan adult & Oxkutzcab, Yucatán & $830.77 \pm 52.91$ & $333.47 \pm 21.83^{\star}$ & $999 \pm 0^{*}$ \\
\hline C. mictlantecuhtli juvenile (pool) & Veracruz & $34.88 \pm 1.04$ & $28.40 \pm 0.33^{*}$ & $45.25 \pm 0.64^{*}$ \\
\hline C. mictlantecuhtli adult (pool) & Veracruz & $43.75 \pm 1.60$ & $33.25 \pm 2.36^{*}$ & $61.75 \pm 2.07^{\star}$ \\
\hline
\end{tabular}

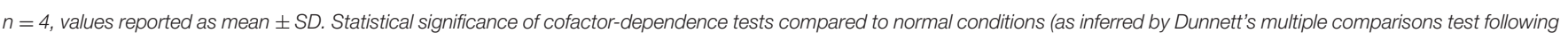
repeated-measures ANOVA) shown as follows: ${ }^{\star} p<0.05,{ }^{\star *} p<0.001,{ }^{\star * *} p<0.0001$. All values represent venom-induced clotting times (s).

thromboelastography traces results for C. culminatus, $C$. mictlantecuhtli, and C. tzabcan; Figure 7 shows the human fibrinogen thromboelastography traces for the three C. molossus localities; Figure 8 shows the human fibrinogenolytic effects for C. tzabcan and C. molossus oaxacus.

Thromboelastography on plasma (Figures 4,5) confirmed the marked procoagulant action of neonate C. culminatus venom on plasma on the STA-R Max assay, whereby a quick and strong clot was formed for the neonate, but not for the adult. The acceleration of clotting time and a strong, stable clot by the $C$. culminatus neonate venom is consistent with the activation of a clotting factor, which was specifically tested for in subsequent experiments (see section Blood Clotting Factor Activation Assay). None of the other venoms showed evidence of clotting factor activation in the plasma experiments (Figures 4, 5).

Thromboelastography on fibrinogen to test for pseudoprocoagulant fibrin-clot formation (Figures 6, 7) or destructive (non-clotting) fibrinogenolysis (Figure 8) also revealed sharp differences between age groups and species. The C. culminatus neonate retained as a background activity the basal pseudoprocoagulant activity widely present in rattlesnakes, but this trait was absent in the adult venoms. Intraspecific variation was evident in the C. tzabcan venoms, with one venom having pseudo-procoagulant activity upon fibrinogen whereas the other lacked this trait. Both neonate and adult C. mictlantecuhtli venoms displayed pseudo-procoagulant activity upon fibrinogen. This was not the case for C. m. oaxacus, while C. m. molossus showed only very slight activity in this regard. Further tests to see if C. tzabcan or C. m. oaxacus destructively cleaved fibrinogen revealed that while $C$. tzabcan did so only to a limited extent, $C$. $m$. oaxacus was extremely fibrinogenolytic, with the fibrinogen levels almost entirely depleted. Venoms were also tested on amphibian (cane toad) plasma, but none of them had any effect (data not shown).

\section{Blood Clotting Factor Activation Assay}

As the prior results indicated that neonate C. culminatus venom was activating a clotting factor, tests were undertaken to test for activation of FII (prothrombin), FVII, FIX, FX, FXI, and XII. Only Factor X returned a strong result (Figure 9A), with prothrombin only being activated at a trace level (Figure 9B) and none of the other factors affected (data not shown). Consistent with the dichotomy observed on other clotting tests, the adult
C. culminatus was 20-fold less potent than the neonate in the activation of FX and displayed no meaningful activity upon prothrombin or any other clotting factor. FX activation by neonate $C$. culminatus venom proved to be highly dependent on both calcium and phospholipids (Figure 10), the absence of which nearly abolished any action of the venom on the zymogen. Thus, the cofactor dependence values on whole plasma for this venom in Table 4 are artificially low due to the back-ground direct clotting of fibrinogen in a pseudoprocoagulant manner.

Intriguingly, C. m. oaxacus and C. mictlantecuhtli (juvenile pool) showed negative values. The [venom + substrate] controls were undertaken to provide the baseline activity of the venom in cleaving the substrate, with this amount to be subtracted from the results for the [venom + substrate + zymogen (FX or prothrombin)] experimental conditions. A negative value, whereby less fluorescence occurred for the [venom + substrate + zymogen] condition than for the [venom + substrate] indicates that in the [venom + substrate + zymogen] condition, less cleaving by the venom was observed than for the [venom + substrate] condition. This suggests that the venom was cleaving the substrate itself while simultaneously binding zymogen, resulting in less venom available to directly cleave the substrate when the zymogen was present. In addition, the interaction with the zymogen did not produce an active product from the cleaved zymogen. The ability to cleave the zymogen without yielding an active product could therefore represent a novel form of anticoagulation, as the zymogen would no longer be available to participate in the normal clotting cascade. This was evaluated experimentally with another fluorometric assay whereby Pseudonaja textilis venom, a well-known prothrombin activator (58), was incubated with intact zymogen and zymogen previously exposed to C. $m$. oaxacus venom for $1 \mathrm{~h}$ at $37^{\circ} \mathrm{C}$. Activation in the C. m. oaxacus-treated zymogen was only $15 \%$ of that observed for the intact zymogen (Figure 11). Prothrombin degradation was further explored via gel electrophoresis [section 1D Polyacrylamide Gel Electrophoresis (SDS-PAGE)].

\section{D Polyacrylamide Gel Electrophoresis (SDS-PAGE)}

1D SDS-PAGE of venoms incubated with prothrombin revealed clear differences in action of toxins from different species on 
C. culminatus neonate (Tlaltizapan, Morelos)

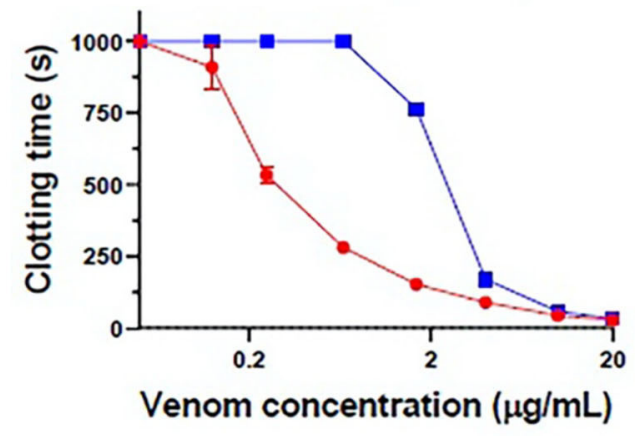

C. tzabcan adult (Solidaridad, Quintana Roo)

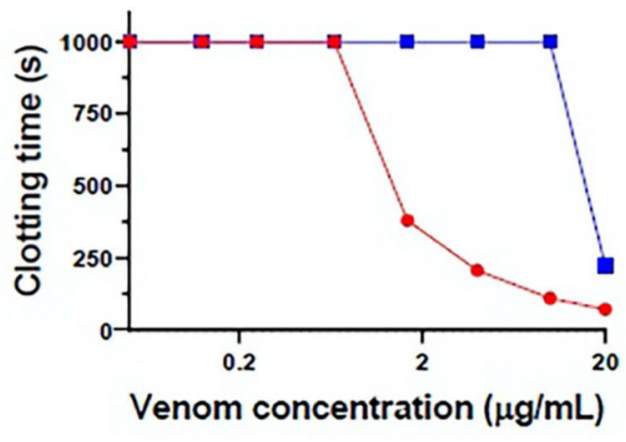

C. mictlantecuhtli juvenile pool (Veracruz)

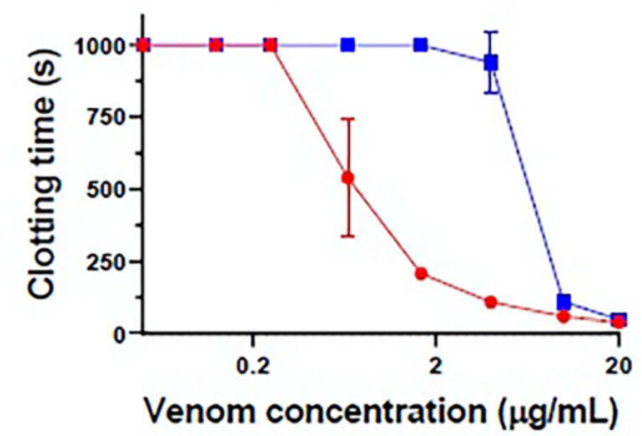

C. culminatus adult (Barranca Honda, Morelos)

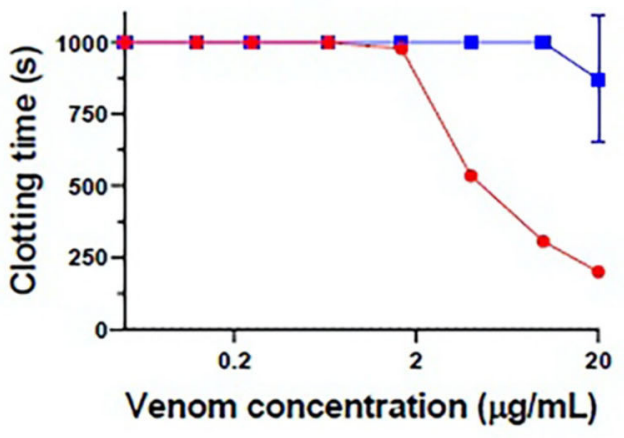

C. tzabcan adult (Oxkutzcab, Yucatan)

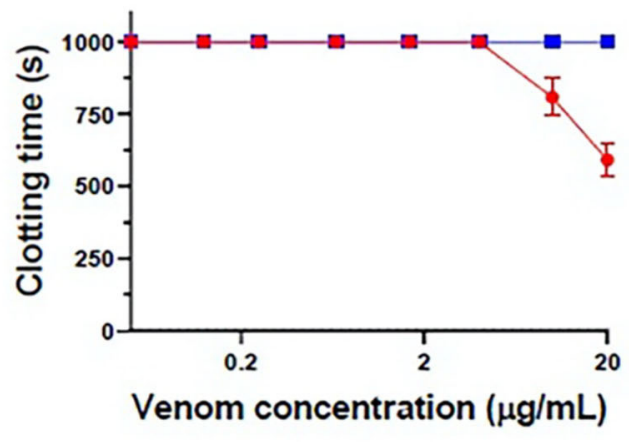

C. mictlantecuhtli adult pool (Veracruz)

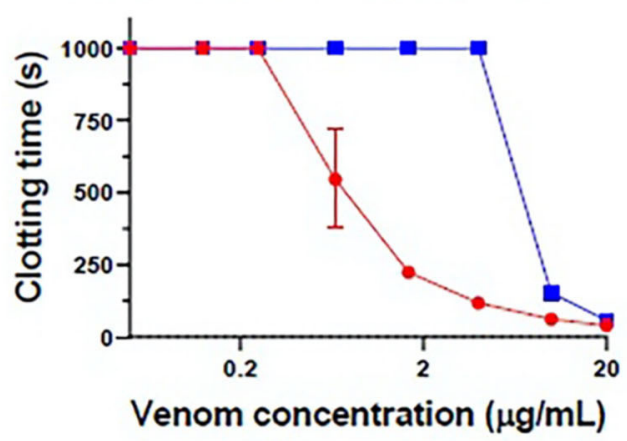

FIGURE 2 | Eight-point dilution curves for six representative venoms against Antivipmyn ${ }^{\circledR}$ antivenom (2.5\%) on human fibrinogen, Red = venom only, blue $=$ venom + antivenom. X-axis is displayed in log form. Negative control $=999+/-0$ s.

this zymogen (Figure 12). In fact, C. m. oaxacus degraded prothrombin into several aberrant by-products spanning the region between the prothrombin and thrombin controls (72 and $36 \mathrm{kDa}$, respectively). On the other hand, C. culminatus (neonate) and $C$. mictlantecuhtli (pool of juveniles) affected the zymogen only weakly, with faint bands appearing in the $50-55 \mathrm{kDa}$ region of the gel. A different neonate C. culminatus sample was used for this assay than in previous tests due to insufficient amount of venom remaining.

\section{DISCUSSION}

\section{Synopsis}

This study aimed to shed light on the evolutionary history and medical consequences of coagulotoxicity in a group of Mexican rattlesnakes of high clinical concern and evolutionary novelty. To this end, we assessed coagulotoxic venom activities in these snake venoms via multiple different assays to produce a robust set of results. We reproduced physiological conditions 


\section{C. culminatus neonate (Tlaltizapan, Morelos)}

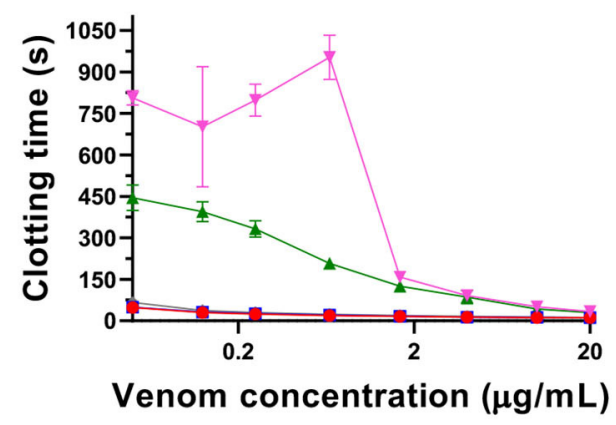

C. culminatus adult (Cruz Pintada, Morelos)

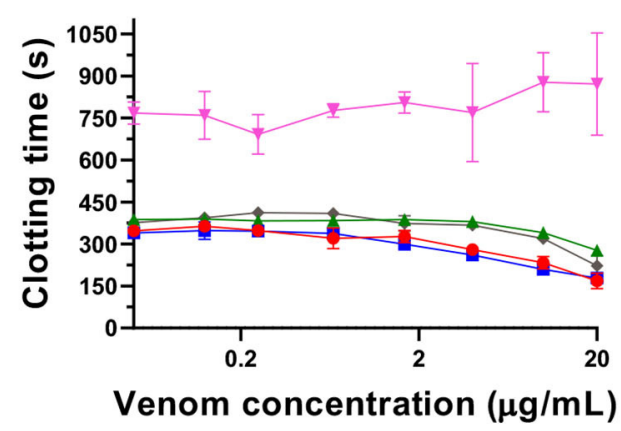

FIGURE 3 | Eight-point dilution curves for C. culminatus venom upon plasma (red lines for venom-only) against Antivipmyn ${ }^{\circledR}$ antivenom (blue lines), 2 mM Prinomastat hydrochloride with 2 min incubation (green lines), 2 mM DMPS with 2 min incubation (pink lines). Spontaneous clotting control $=444.87 \pm 26.73$ s. Prinomastat negative control $=450.02 \pm 57.33 \mathrm{~s}$. DMPS negative control $=626 \pm 36.23 \mathrm{~s}$.

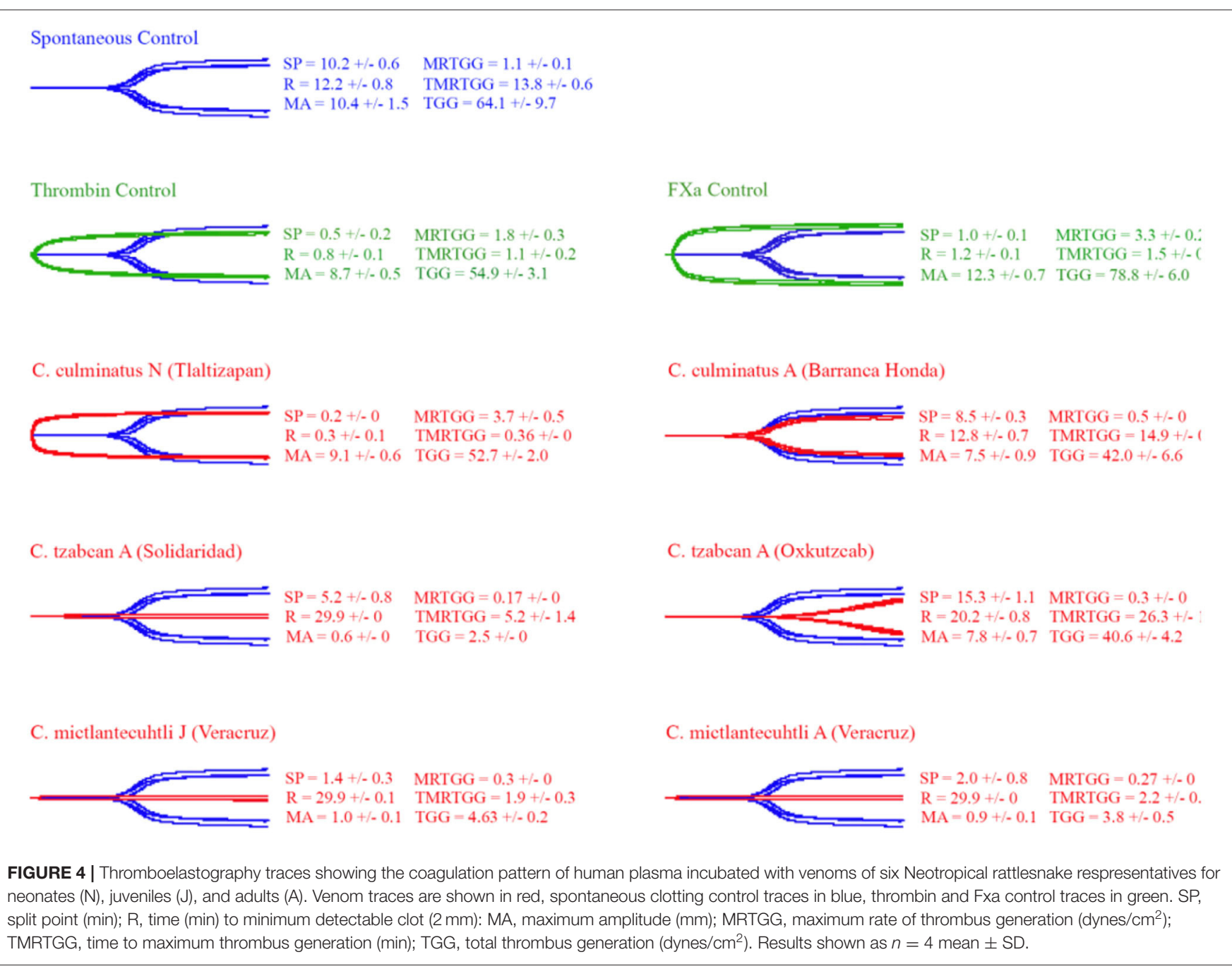

as best as possible to accurately characterize the venom effects. In doing so we revealed a previously unknown ontogenetic variation in C. culminatus, whereby neonates are potently procoagulant through the activation of Factor X, but adults are pseudo-procoagulant in that they cleaved fibrinogen into unstable, short-lived fibrin clots, thus contributing to a net anticoagulant state by depleting fibrinogen levels. The $C$. culminatus FX activation was shown to be biochemically 
Spontaneous Control

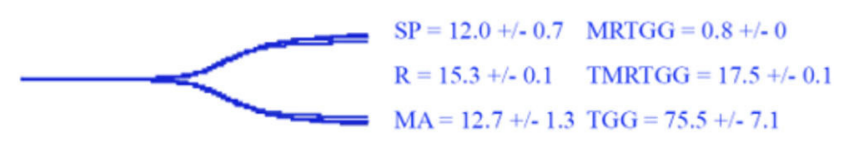

FXa Control

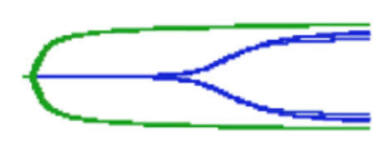

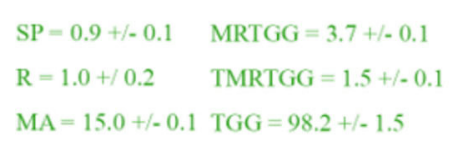

$\mathrm{R}=1.0+/ 0.2 \quad$ TMRTGG $=1.5+/-0.1$
Thrombin Control

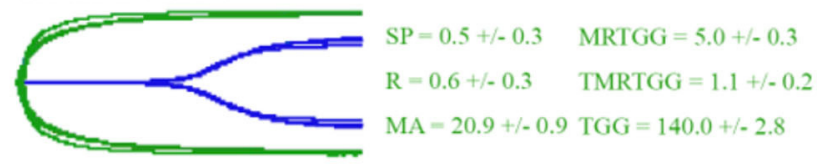

C. m. oaxacus (Sierra de Cuatro Venados)

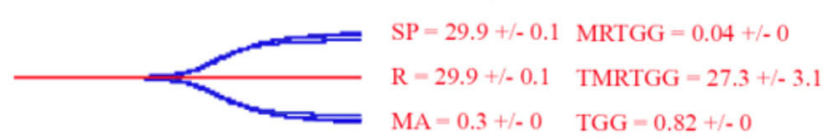

$\mathrm{MA}=0.3+/-0 \quad \mathrm{TGG}=0.82+/-0$
C. m. oaxacus (Oaxaca)

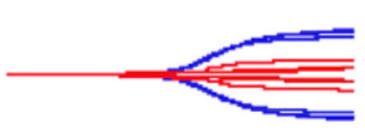

$\mathrm{SP}=11.9+/-1.8$
$\mathrm{R}=21.8+/-5.7$

$\mathrm{MA}=4.1+/-0$
MRTGG $=0.3+/-0.2$

TMRTGG $=19.8+/ .9$

$\mathrm{TGG}=15.3+/-8$

C. m. molossus (Houston)

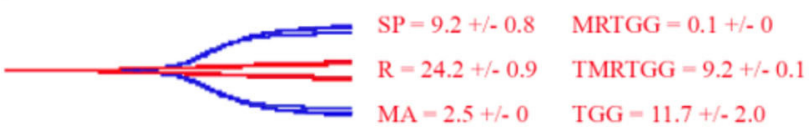

FIGURE 5 | Thromboelastography traces showing the coagulation pattern of human plasma incubated with venoms of three C. molossus specimens of two subspecies (C. m. molossus and C. m. oaxacus). Venom traces are shown in red, spontaneous clotting control traces in blue, thrombin and Fxa control traces in green. SP, split point (min); R, time (min) to minimum detectable clot (2 mm); MA, maximum amplitude (mm); MRTGG, maximum rate of thrombus generation (dynes/cm²); TMRTGG, time to maximum thrombus generation (min); TGG, total thrombus generation (dynes/cm²). Results shown as $n=4$ mean \pm SD.

extremely reliant upon calcium and phospholipids. These results reinforce what a dynamic trait venom is, as the other species depleted fibrinogen levels either by pseudoprocoagulant actions on fibrinogen or through destructive (nonclotting) cleaving.

\section{Variations in Venom Biochemistry}

Strikingly, we observed that venom from neonate C. culminatus clotted human plasma in our in vitro assay in 10-15 s, comparable to potently procoagulant snakes such as several Australian elapids $(59,76,107,110)$. We demonstrated that this activity was due to the activation of Factor $\mathrm{X}$. The metalloprotease inhibitors Prinomastat and (to a much lesser degree) 2,3-dimercapto1-propanesulfonic acid (DMPS) were effective in neutralizing the Factor $\mathrm{X}$ activation, revealing the activity to be driven by SVMP.

The unmistakably true procoagulant activity of $C$. culminatus venom was an unexpected finding in light of previous literature unanimously reporting a lack of any such trait in this species $(32,44)$. However, these studies did not include the clotting cofactors calcium or phospholipids in the assay conditions, which we show both clotting factors be critical through multiple assays in this study, and such cofactor dependence has long been documented in snake venoms (111). In addition to the venom activation of FX into FXa being obligately calcium-dependent, the bioactivity of the endogenous FXa which is produced by the venom is also obligately dependent upon calcium so even for venoms which are able to activate FX in the absence of calcium, their activity would be missed in assays which relied on protocol designs. The discrepancy between our results and previous literature is almost certainly due to the omission of clotting cofactors $\mathrm{Ca}^{2+}$ and phospholipids in prior research that relied upon the method developed in 1983 by Theakston and Reid (64), which did not include either clotting cofactor and has been largely followed with only minor modifications in toxicity studies of Mexican Neotropical rattlesnakes $(32,44,112)$. Thus, calciumobligate activities such as the Factor $\mathrm{X}$ activation discovered in this study would not be observable in assays lacking the clotting cofactors.

Such high levels of calcium dependence for procoagulant zymogen activation (Factor $\mathrm{X}$ or prothrombin) have been observed in other venomous snake lineages, including other pit vipers such as Bothrops atrox (113), true vipers of the genus Echis (56), Australian elapids (107) the genus Atractaspis within the Lamprophiidae family (57), and the colubrid genera Dispholidus and Thelotornis (74). In contrast, other genera are known to activate zymogens with much lower levels of calcium dependence, such as some species of Echis (56), and 
Thrombin Control

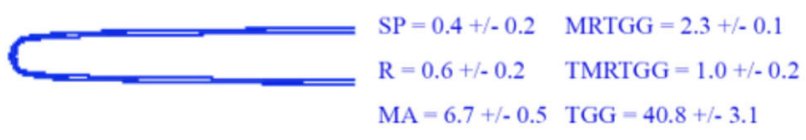

C. culminatus N (Tlaltizapan)

C. culminatus A (Barranca Honda)
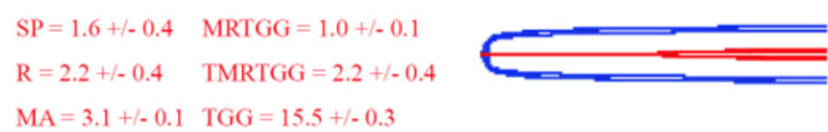

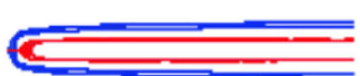

C. tzabcan A (Solidaridad)

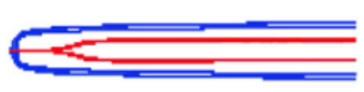

C. tzabcan A (Oxkutzcab)

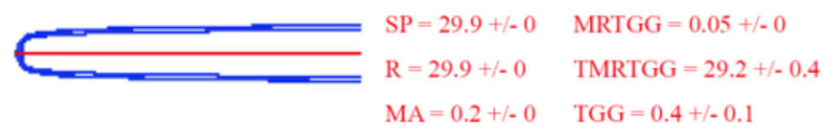

C. mictlantecuhtli J (Veracruz)

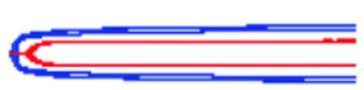

$\begin{array}{ll}\mathrm{SP}=1.7+/-0.2 & \mathrm{MRTGG}=1.1+/-0.1 \\ \mathrm{R}=2.3+/-0.1 & \text { TMRTGG }=2.3+/-0.2\end{array}$

$\mathrm{MA}=3.6+/-0.1 \quad \mathrm{TGG}=19.1+/-0.6$
C. mictlantecuhtli A (Veracruz)

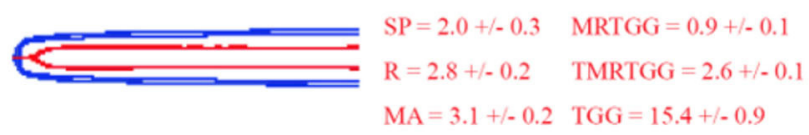

FIGURE 6 | Thromboelastography traces showing the coagulation pattern of human fibrinogen incubated with venoms of six Neotropical rattlesnake respresentatives for neonates (N), juveniles (J), and adults (A). Venom traces are shown in red, thrombin control traces in blue. SP, split point (min); R, time (min) to minimum detectable clot (2 mm); MA, maximum amplitude (mm); MRTGG, maximum rate of thrombus generation (dynes/ $\left.\mathrm{cm}^{2}\right)$; TMRTGG, time to maximum thrombus generation (min); TGG, total thrombus generation (dynes $/ \mathrm{cm}^{2}$ ). Results shown as $n=4$ mean $\pm \mathrm{SD}$.

Thrombin Control

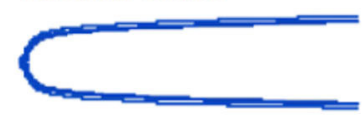

$\mathrm{SP}=0.4+/=0.2 \quad \mathrm{MRTGG}=2.9+/-0.6$

$\mathrm{R}=0.5+/-0.2 \quad$ TMRTGG $=0.9+/-0.2$

$\mathrm{MA}=10.9+/-1.0 \quad \mathrm{TGG}=72.9+/-5.1$

\section{C. m. oaxacus (Oaxaca)}

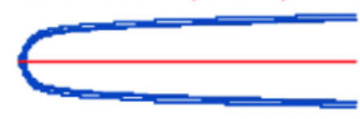

$\mathrm{SP}=29.9+/-0$

$\mathrm{R}=29.9+/-0$

$\mathrm{MA}=0.2+/-0$
MRTGG $=0.02+/-0$

TMRTGG $=29.1+/=0.3$

$\mathrm{TGG}=0.1+/-0$
C. m. oaxacus (Sierra de Cuatro Venados)

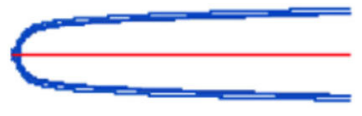

C. m. molossus (Houston)

$$
\begin{array}{ll}
\mathrm{SP}=9.1+/-0.8 & \mathrm{MRTGG}=0.1+/-0 \\
\mathrm{R}=29.9+/-0.1 & \mathrm{TMRTGG}=9.1+/-1.0 \\
\mathrm{MA}=1.0+/-0 & \mathrm{TGG}=4.53+/-0.1
\end{array}
$$

FIGURE 7 | Thromboelastography traces showing the coagulation pattern of human fibrinogen incubated with venoms of three C. molossus specimens of two subspecies (C. m. molossus and C. m. oaxacus). Venom traces are shown in red, thrombin control traces in blue. SP, split point (min); R, time (min) to minimum

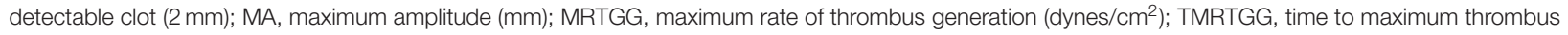
generation (min); TGG, total thrombus generation (dynes $/ \mathrm{cm}^{2}$ ). Results shown as $n=4$ mean \pm SD.

the Australian elapid genera Oxyuranus and Pseudonaja $(58,59)$. Venom-induced FX activation by neonate C. culminatus was also highly dependent on phospholipids, which appear to be nearly as crucial as $\mathrm{Ca}^{2+}$. This further highlights the importance for venom coagulotoxicity assays in vitro to include both cofactors so as to avoid skewing results. 
Fibrinogen Spontaneous Control

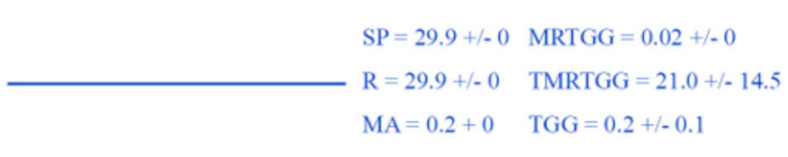

C. tzabcan A (Oxkutzcab)

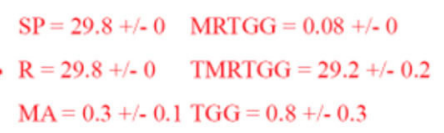

C. m. oaxacus (Sierra de Cuatro Venados)

$$
\begin{array}{ll}
\mathrm{SP}=29.9+/-0 & \mathrm{MRTGG}=0.06+/-0 \\
\mathrm{R}=29.9+/-0 & \text { TMRTGG }=29.2+/-0.3 \\
\mathrm{MA}=0.2+/-0.1 & \mathrm{TGG}=0.5+/-0.1
\end{array}
$$

Fibrinogen Control + Thrombin

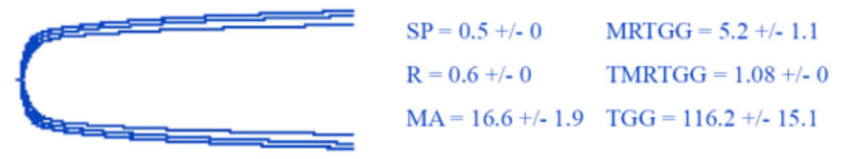

C. tzabcan A (Oxkutzcab) + Thrombin

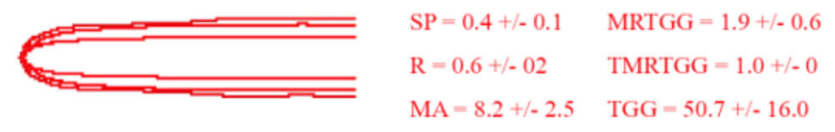

C. $\mathrm{m}$. oaxacus (Sierra de Cuatro Venados ) + Thrombin

$$
\begin{array}{ll}
\mathrm{SP}=10.6+/-8.3 & \mathrm{MRTGG}=0.1+/-0 \\
\mathrm{R}=29.9+/-0 & \mathrm{TMRTGG}=15.9+/-12.2 \\
\mathrm{MA}=0.6+/-0.4 & \mathrm{TGG}=2.0+/-1.9
\end{array}
$$

FIGURE 8 | Thromboelastography traces showing the fibrinogenolytic action of venoms from C. tzabcan (Oxkutzcab) and C. m. oaxacus (Sierra de Cuatro Venados). Venom traces are shown in red, spontaneous and thrombin control traces in blue. SP, split point (min); R, time (min) to minimum detectable clot (2 mm); MA, maximum amplitude (mm); MRTGG, maximum rate of thrombus generation (dynes/cm²); TMRTGG, time to maximum thrombus generation (min); TGG, total thrombus generation (dynes $/ \mathrm{cm}^{2}$ ). Results shown as $n=4$ mean \pm SD.

A

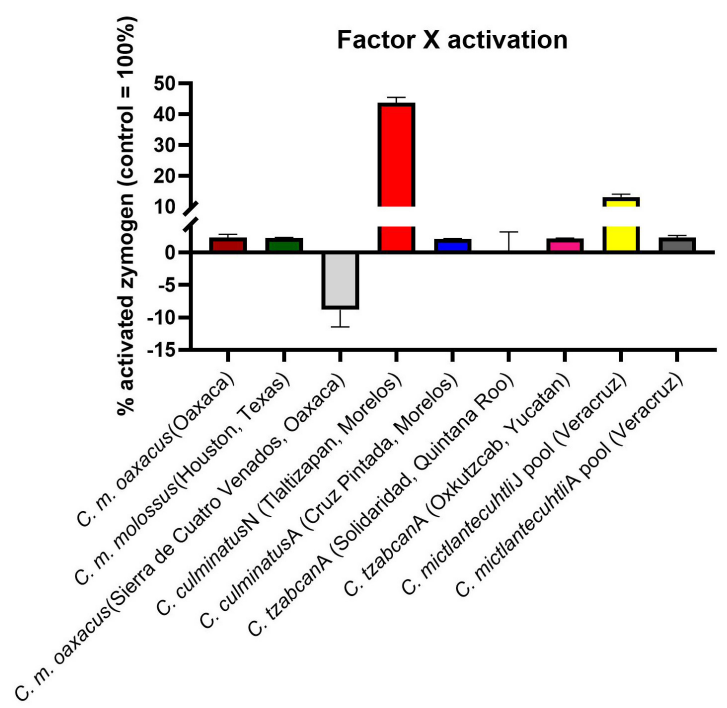

B

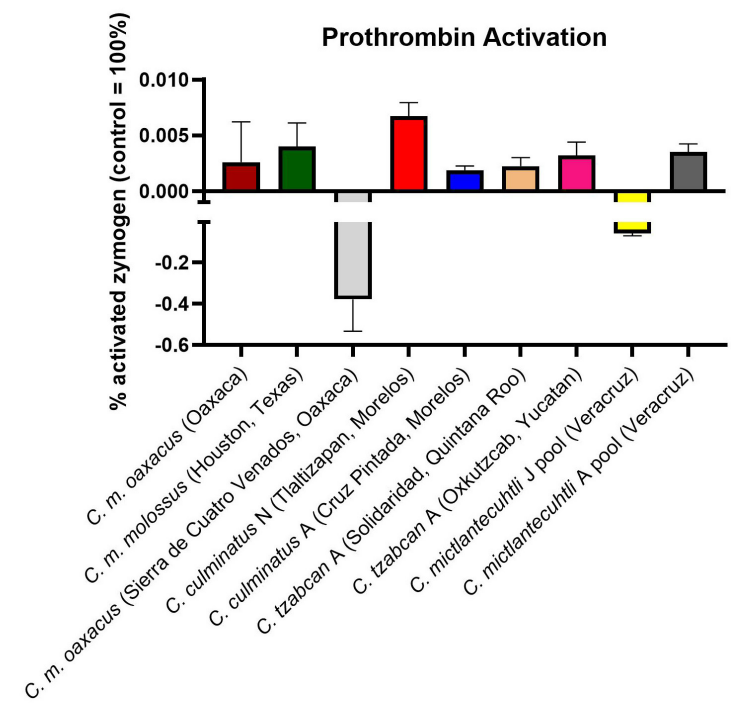

FIGURE 9 | Fluorometry graphs showing activation of FX (A) and prothrombin (B) by selected rattlesnake venoms. Activation is expressed as the relative percentage of zymogen converted to its active form against a benchmark positive control incubated with thrombin and FXa, respectively (i.e., 100\% active enzyme). Note the difference in Y-axis between FX activation and prothrombin activation, indicating considerably greater potency for the former. Values are $n=3$ mean \pm SD.

The SVMP toxin class has been previously shown to be responsible for Factor $\mathrm{X}$ activation in a wide range of snakes, including the related pit viper genus Bothrops (113) and true vipers such as Bitis worthingtoni $(76,114)$. Thus, this trait either represents a remarkable case of functional convergence in the neofunctionalisation of an ancestral tissue-destroying metalloprotease or indicates that FX activation is an ancient trait that has been amplified on 


\section{FX activation cofactor dependence}

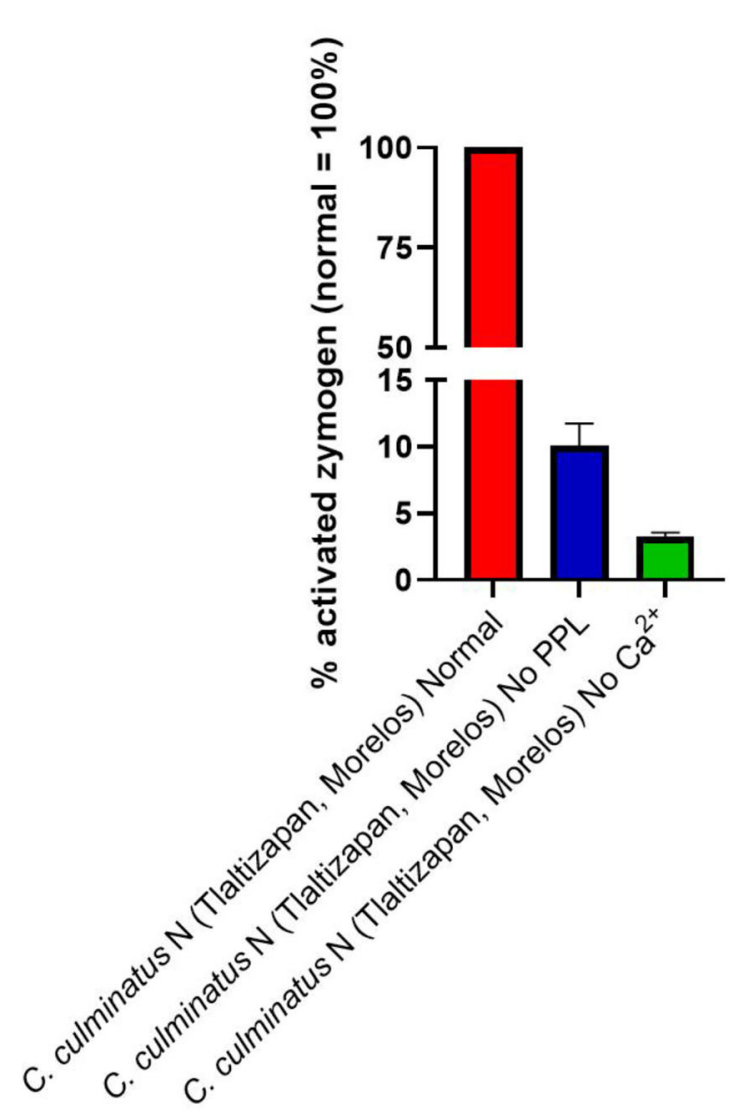

FIGURE 10 | Fluorometry graph showing activation of FX by venom from a neonate C. culminatus specimen with and without coagulation cofactors (Ca ${ }^{2+}$ and phospholipids). Activation is expressed as the relative percentage of zymogen converted to its active form, with the normal condition (i.e., both Ca ${ }^{2+}$ and phospholipidss present in the incubation) as the $100 \%$ benchmark. Values are $n=3$ mean \pm SD.

multiple convergent occasions but is only maintained at trace levels in most species. The answer to this question would require sequencing of the enzyme responsible for FX activation and reconstructing its molecular evolutionary history through the construction of a robustly supported molecular phylogenetic tree.

From a phylogenetic point of view, C. culminatus is consistently retrieved as an early divergence from the rest of the C. durissus complex $(18,26)$. Therefore, the true procoagulant venom phenotype observed in this species might have evolved independently or represented the ancestral state for this clade. The latter possibility was investigated by testing the venom of C. molossus, part of the sister clade to the C. durissus complex alongside C. basiliscus, C. ornatus, and C. totonacus (26, 27). However, our thromboelastography and factor activation results revealed only a weakly pseudo-procoagulant venom action for the nominate subspecies C. m. molossus and distinctly anticoagulant patterns for a $C$. $m$. oaxacus representative, which greatly degraded fibrinogen to a point where addition of thrombin was unable to form a clot. This is consistent with previous studies reporting high fibrin(ogen)olysis across the three subspecies of C. molossus $(95,115,116)$ and does not support a procoagulant ancestral condition for the C. durissus group. Thus, this trait likely stems either from convergent amplifications of a basal FX-activating SVMP or convergent evolutions of neofunctionalised SVMPs in Viperidae.

The ability of the serine-protease inhibitor AEBSF to neutralize the pseudo-procoagulant activity of C. mictlantecuhtli venom demonstrated that this venom activity is driven by kallikrein-type serine proteases. The differential reliance upon $\mathrm{Ca}^{2+}$ extended to the pseudo-procoagulant actions on fibrinogen, with all the venoms acting notably more slowly (up to half as fast) in the absence of $\mathrm{Ca}^{2}$ (Table 4). The relative reliance upon phospholipids has also been shown to be a highly labile trait $(66-73,117)$. While the effect is less pronounced than for $\mathrm{Ca}^{2+}$, it is still a significant variable, showing extreme variation within a genus or even within different geographic ranges of a single species $(50-53,56-59,107)$. Notably, our cofactor dependence assay revealed a consistently significant acceleration of fibrinogen clotting in the absence of phospholipids. This phenomenon 


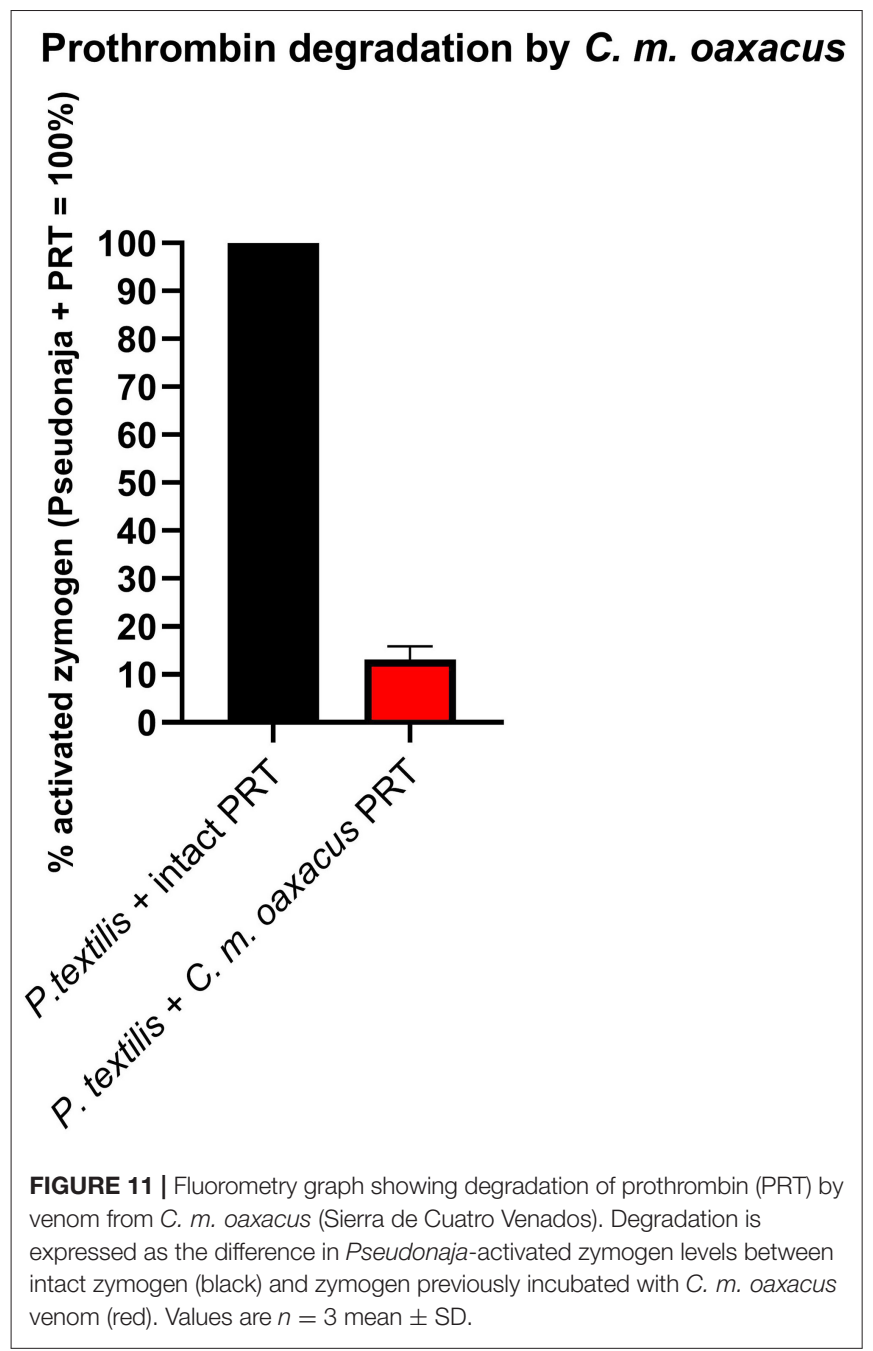

was already observed in several Asian pitvipers of the genus Trimeresurus (52) and in the Australian elapid genus Pseudonaja (58). The biochemical dynamics underlying this pattern are unclear and warrant further research.

Another novel activity documented in this study was degradation of prothrombin by C. $m$. oaxacus, a phenomenon previously reported in several viper species $(118,119)$ but rarely in rattlesnakes (120). Such an activity would create a net anticoagulant state by depleting the amount of this endogenous clotting factor available for participation in the clotting cascade. This activity was first inferred from the negative values obtained in prothrombin activation tests, and then confirmed by two additional assays: first by incubating the venom with prothrombin, then adding a known prothrombin trigger, and comparing the results to the same trigger added to prothrombin that had not been exposed to C. mo. oaxacus venom; and secondly by an SDS-PAGE assay, whereby C. $m$. oaxacus produced several aberrant degradation by-products of higher molecular mass than thrombin. The net decrease in activity in the FX zymogen activation studies for C. $m$ oaxacus is consistent with this species also degrading FX in addition to prothrombin. However, Factor X degradation was unable to be further examined due to running out of venom supplies. The fact that the venom produced the same negative values in the Flouroskan tests as was the case for prothrombin and with these negative values for prothrombin being confirmed by additional tests as indeed being reflective of degradation events, this is strongly suggestive of Factor X also being degraded by this venom. Future work to confirm this would involve assays such as were undertaken for prothrombin degradation in this study: (a) incubating the venom with Factor X, then adding a known Factor $\mathrm{X}$ trigger, and comparing the results to the same trigger added to Factor X that had not been exposed to C. mo. oaxacus venom; and (b) SDS-PAGE gels to ascertain relative cleavage products to determine if aberrant cleavage products were formed.

As discussed earlier, such stark individual variations are commonplace among rattlesnakes. C. molossus occurs throughout a vast range spanning from the southwestern US to southern Mexico, with blurred geographic and genetic boundaries among subspecies $(10,27)$. Our small sample size does not allow for documentation of subspecies- and populationlevel venom variability in this species, which therefore should be the subject of future research in order to elucidate to what extent venom variation reflects biogeographical and/or ecological drivers in the C. molossus complex.

\section{Prey-Capture Evolutionary Implications}

The procoagulant activation of zymogens into their active forms (e.g., FX into FXa; prothrombin into thrombin) in prey animals would result in rapid incapacitation due to stroke, induced by large blood clots. Interestingly, procoagulant venom activity via FX activation in C. culminatus appears to be an ontogenetic trait, with the shortest and longest clotting times for both plasma and fibrinogen observed in neonates and adults, respectively. This is corroborated by our thromboelastography and fluorometry results in terms of time to clot formation and FX zymogen activation. Ontogenetic shifts in venom composition and/or activity have been extensively documented in a variety of rattlesnake species and lineages $(60,112,121-124)$, particularly with respect to a pattern of loss of crotoxin-like neurotoxic $\mathrm{PLA}_{2} \mathrm{~S}$ (Type II phenotype) in favor of hemorrhagic SVMPs (Type I phenotype) as the snake ages $(38,45,46)$. This phenomenon is recurrent in the $C$. durissus complex $(35,43,45)$. Such agedriven changes in venom composition are generally thought to stem from shifts in prey preference between juvenile and adult snakes $(10,121,122)$, as seen in a variety of snakes ranging from Australian elapids (110) to lancehead pit vipers of the genus Bothrops $(113,125)$. However, our current knowledge-albeit fragmentary-points to C. durissus, C. simus, and C. tzabcan being rodent specialists throughout their life (10, 24, 126-129). While only scarce information is available for C. culminatus, reports indicate a rodent-centered diet as well $(10,23,24,130)$. This is supported by our thromboelastography results showing a strikingly potent procoagulant effect of $C$. culminatus venom on human plasma as opposed to no apparent activity at all on amphibian plasma, suggesting specialization for an endothermbased diet. By contrast, the venoms of other vipers such as Bitis worthingtoni and several Bothrops representatives are known to 


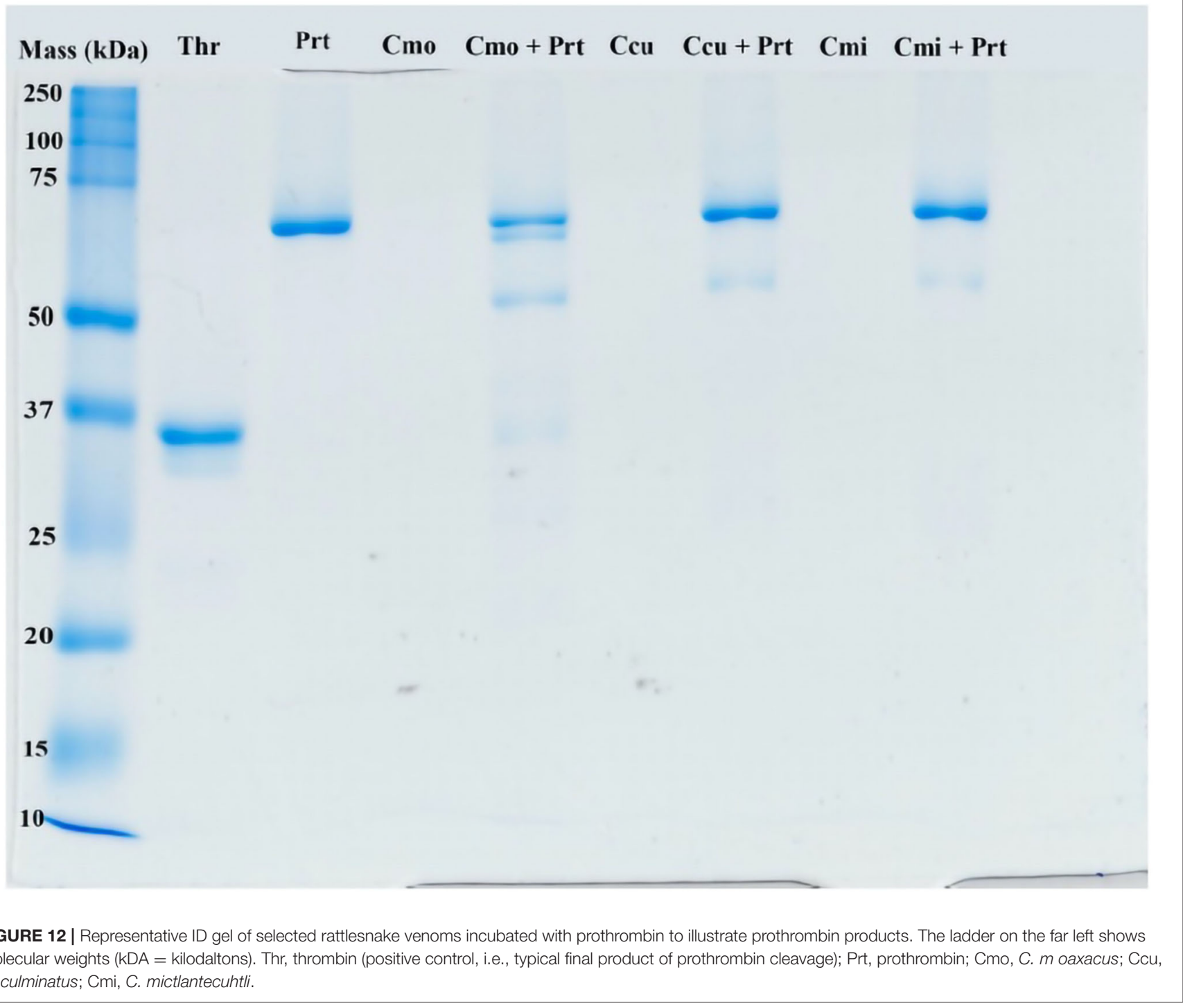

activate both mammalian and amphibian plasma, with potency showing a clear correlation with degree of specialization on amphibian prey $(113,114)$. The Factor $\mathrm{X}$ zymogen differs significantly in mammals compared to amphibians and diapsids (i.e., reptiles and birds). Future work should investigate the lineage-specific motifs that guide such differential activation. Testing of C. culminatus venom on reptile plasma (e.g., lizard) would be a logical follow-up to corroborate our findings, since this snake occurs in dry habitats at mid- to high elevations in southwestern Mexico where other reptiles abound (23, 130, 131).

It has been suggested that potent, fast-acting toxins possibly serve as a means for small-sized snakes to rapidly incapacitate prey using a substantially lower amount of venom than adults are able to inject $(122,126)$ and/or to quickly immobilize prey items $(113,122,126)$. Intriguingly, while nearly all members of the C.durissus complex present variable quantities of crotoxin in their venom, C. culminatus lacks this neurotoxin entirely $(35,45)$. By contrast, this species possesses a significantly higher percentage of SVMPs than C. tzabcan and C. simus, with neonates and juveniles possessing metalloproteases not found in adults and vice versa $(44,45)$. It is therefore possible that highly procoagulant SVMPs in early-stage C. culminatus play a role akin to that of crotoxin-like neurotoxins in other members of the $C$. durissus complex and other rattlesnake lineages, as factoractivating SVMPs are known to induce rapid death by stroke in small-sized animals (132). Neonate and juvenile rattlesnakes require meals as early as possible to avoid starvation and support high rates of growth $(10,133)$. Thus, a highly potent toxic component in neonate rattlesnake venom may greatly improve prey-capture and survival into adulthood. Our results align with the observations of Margres et al. (134) in the equally nonneurotoxic species C. adamanteus, with higher venom toxicity in juveniles compared to adults. This indicates that such a pattern may be widespread among rattlesnakes beyond the simplistic Type I vs. Type II categorization, an intriguing possibility that invites further research. 
While C. culminatus possesses a distinctly Type I venom phenotype $(44,45)$, the SVMP-driven procoagulant activity observed in this study might serve a functional role analogous to that of neurotoxic $\mathrm{PLA}_{2}$ components in Type II venoms from juveniles of other species. Hence, a general classification such as the Type I vs. Type II dichotomy devised by Mackessy (38) might overlook peculiar toxic activities of venom in certain species and is therefore not reflective of the greater complexity present in biological reality. It must be noted, however, that SVMPs are considerably larger than crotoxin isoforms in terms of molecular weight, which might delay absorption via the bloodstream and/or lymphatic system, as documented for $C$. simus venom (135). Thus, further research on the ecology and natural history of this species alongside the pharmacokinetics of its venom is necessary in order to understand how procoagulant venom activity translates to a functional role for the animal.

The pseudo-procoagulant activity of the venoms also showed extreme taxon-specificity, being active on mammalian plasma but not amphibian plasma. The fibrinopeptide domain at which thrombin cleaves fibrinogen to form fibrin clots differs sharply in mammals vs. the homologous region of amphibians/diapsids (Figure 13). While the precise region at which the venoms cleave fibrinogen to form the unnatural fibrin clots has not been yet elucidated for these species, we observed a clear difference in clot strength between the thrombin-activated fibrinogen and that of the venom-activated fibrinogen (Figure 3). Much has been said in the literature about the inability of snake venom fibrionogenolytic enzymes to stabilize fibrin clots through the activation of Factor XIII, leading to weaker clots (136-142). However, this study (Figure 3) and previous research alike reported that venom-induced fibrin clots were still considerably weaker than thrombin-induced ones, even in the absence of FXIII, which is indicative of the venoms cleaving the fibrinogen differently relative to thrombin. Thus, snake venoms either cleave at a different region of the fibrinopeptide domain or at additional sites in the full-length fibrinogen chains to disrupt the latticework. Previous work on some species has revealed that some cleave only fibrinopeptide $\mathrm{A}$, while others cleave only fibrinopeptide $\mathrm{B}$, but with both at the same cleavage site as thrombin (143). However, cleaving at these sites should produce the same clot strengths as thrombin, yet they yield weaker clots. This suggests that if both fibrinopeptides are being cleaved at sites identical to those targeted by thrombin, yet produce weak, unstable, and short-lived clots, then the venoms are cleaving at additional sites, as would be the case for destructive (non-clotting) venoms. Such sites have been identified for some venoms $(143,144)$. Overall, however, this aspect of venom biochemistry is poorly researched. Future work should investigate whether the pseudo-procoagulant activity is mammal-specific by testing additional venoms on non-mammalian plasma. In addition, it is recommended to investigate the specific cleavage site to ascertain the differential nature of the cleavage between thrombin and the venoms.

\section{Clinical Implications}

As previously discussed, procoagulant activation of zymogens would rapidly incapacitate prey animals via thrombosis.
Conversely, the venom is diluted into a much larger blood volume in human bite victims, which typically does not result in stroke, although this has been noted on occasion $(145,146)$. Instead, when venom is diluted throughout a large blood volume, venom-induced consumption coagulopathy (VICC) occurs via depletion of clotting factors following excessive activity of the coagulation cascade $(147,148)$. This net anticoagulant state can result in death via internal bleeding.

Our findings demonstrate that the FX-activating procoagulant action of neonate C. culminatus venom is not neutralized by Antivipmyn ${ }^{\circledR}$, one of the most frequently used antivenom products in Mexico. A logical explanation is that Antivipmyn ${ }^{\circledR}$ does not include C. culminatus venom in its immunizing mixture, relying on venom from adult $C$. simus specimens instead (112). C. simus has been recently split into C. ehecatl and C. mictlantecuhtli throughout most of its Mexican range (26), which is likely to affect antivenom manufacturing in turn. To our knowledge, no snake antivenom is produced using venom from juvenile individuals, and this is due to practical constraints of lower venom yields from smaller snakes. Venom from this species complex lacks the metalloprotease-driven true procoagulant trait, being instead pseudo-procoagulant via kallikrein-type serine proteases as shown in this work and previous studies (32, 44, 149). The clinical effects of this toxic activity would be VICC via depletion of fibrinogen following formation of unstable fibrin clots by serine proteases, as reported for multiple other species (51, 52). This SVSP-based pseudo-procoagulant activity was drastically reduced by Antivipmyn ${ }^{\circledR}$ in our assay for all venoms possessing this activity (and by AEBSF as well in the case of $C$. mictlantecuhtli). Our results therefore confirm extensive crossreactivity for Antivipmyn ${ }^{\circledR}$ against pseudo-procoagulant SVSPs in contrast to the failure against the neonate C. culminatus Factor $\mathrm{X}$ activation.

The BIRMEX ${ }^{\circledR} \quad$ (Faboterápico polivalente antiviperino precio), antivenom, widely marketed in Mexico alongside Antivipmyn ${ }^{\circledR}$ to treat rattlesnake envenoming, has $C$. basiliscus and Bothrops asper as its main immunizing species $(112,150)$. Although this product displays a high degree of cross-reactivity across multiple rattlesnake species (32, 150), further testing is recommended to determine whether it is able to neutralize the true procoagulant activity found in $C$. culminatus. However, as the immunizing venom composition does not include this species, it is unlikely to produce a more promising result.

Our findings draw attention to the pivotal importance of which immunizing venoms are chosen for antivenom production, including the critical need to ascertain ontogenetic changes. Such antivenom issues have been noted for other genera such as Pseudonaja (Australian brown snakes), with juvenile venoms rich in neurotoxic three-finger peptides to specialize on lizard prey, and adult venom rich in the FactorXa:FactorVa toxin complex to prey upon mammals as well at later life stages (58, $59,110,151)$. Thus, the antivenom raised against adults performs poorly against neonates due to the pronounced differences in venom biochemistry.

Unlike antivenom, the commercially available metalloprotease inhibitor Prinomastat was able to suppress the procoagulant 


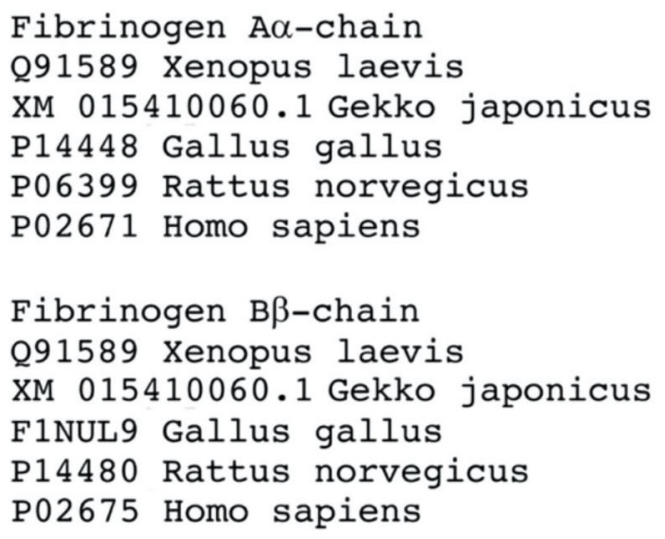

\section{GGIESOGGSIRGPRISESKAEADCKOEKNWPICSDEDWGP STFEEHGGGVRGPRIVEHKAQSDSKQDKNWPLSADDDWGS TTFEKEGGGGRGPRILENMHESSSKYEKNWPISVDDDWGT SEFIEAGGDIRGPRIVER-QPSQSK-ETDWPFSSDEDWNH GDFLAEGGGVRGPRVVER-HQSASK-DSDWPFSSDEDWNY}

FIGURE 13 | Sequence alignment of the activation cleavage sites. Cleavage site of normal thrombin is shown in green, however the venom induced cleavage sites remain to be elucidated for these venoms. There are however clear sequence differences downstream of the known thrombin cleavage site that are distinct between mammals and amphibians/diapsids.

action of neonate C. culminatus venom. However, the inhibitor DMPS performed poorly compared to Prinomastat, indicating that Prinomastat has greater potential as a field-deployable, temperature-stable, first-aid measure. Further problematic for DMPS is its intrinsic anticoagulant action upon plasma (elevating spontaneous clotting times) that might exacerbate disruption of blood coagulation in a real-life VICC scenario. Such a marked divergence may be ascribed to the different action of the two molecules. DMPS is a metal chelator, commonly used to treat heavy metal poisoning $(152,153)$, that binds the $\mathrm{Zn}^{2+}$ ions required for SVMPs to function (106). In contrast, peptidomimetic hydroxamate-based inhibitors like Prinomastat directly inactivate the activity of metalloproteases by binding to their catalytic site in combination with chelation of $\mathrm{Zn}^{2+}$ $(105,154)$. Thus, it is possible that DMPS is slower acting and/or requires a higher concentration to effectively hamper SVMP activity compared to Prinomastat. This was corroborated by preliminary tests showing that DMPS at a $20 \mathrm{mM}$ concentration incubated with venom for $20 \mathrm{~min}$ was more efficient in neutralizing venom effects than at $2 \mathrm{mM}$ for $2 \mathrm{~min}$. Such a prolonged venom-inhibitor proximity would be unlikely to occur in a dynamic system like the bloodstream. Thus, investigations into the efficacy of inhibitors should prioritize those which are fast acting. It should also be noted that SVMPs are a highly diverse toxin family consisting of three classes, each of which is characterized by different structures and active domains with important consequences for their toxic activity (132). Thus, it is possible that the metalloproteases found in Echis venom, which were shown to be neutralized by DMPS (106) and by ion chelators in general better than by peptidomimetic inhibitors (105) differ from those present in C. culminatus to an extent where crossreactivity is poor for DMPS. However, the study that examined the suitability of DMPS for neutralizing Echis venoms (106) used different methodologies (e.g., a kinetic fluorogenic assay to assess the effect of DMPS and other chelators on plasma clotting and SVMP activity) and thus comparing the relative potency with the poor neutralization results obtained in this study is impossible. Future work should undertake head-tohead comparisons between Prinomastat and DMPS using the presently used methodology and with a larger species pool (including Echis) to ascertain if DMPS consistently performs less efficiently than Prinomastat. However, in another study DMPS was conspicuously unable to neutralize Daboia russelii venom (155), which exerts its powerfully procoagulant effect via SVMPinduced Factor $\mathrm{X}$ activation like the neonate $C$. culminatus venom in this study. This suggests two future hypotheses to test. First, that the SVMPs in the two venoms, and thus presumably the FX activators in other viper venoms such as Bothrops, share a common molecular ancestry, putatively all being P-IIId SVMPs, whereby two lectin peptides are covalently linked to the SVMP enzyme. This would in turn suggest that DMPS is unable to neutralize P-IIId SVMPs in general. The prior work on DMPS examined only E. carinatus and E. ocellatus, which are both PIIIa rich venoms but not P-IIId rich like E. coloratus and putatively E. leucogaster and E. pyramidum leakeyi (56). Thus, future work should test a broader diversity of Echis to determine the efficacy of DMPS in neutralizing venoms rich in P-IIId SVMPs.

In recent years, several studies have proposed the use of small molecule inhibitors as an adjunct treatment for snakebite envenoming, to be administered before or alongside antivenom (105, 106, 156, 157). Both Prinomastat and DMPS are already licensed and widely marketed worldwide and can be administered outside a hospital setting (even via oral ingestion for DMPS), facilitating their use in real-life envenoming situations. Taken together, our observations indicate that $C$. culminatus possesses a peculiar venom phenotype that hampers antivenom cross-reactivity with its closest relatives in Mexico and encourages the use of metalloprotease inhibitors as an adjunct treatment. However, it should be noted that, while small molecule inhibitors have shown considerable potential in countering symptoms of snakebite, their repurposing for use as an adjunct 
treatment for envenomation will require in vivo investigations and clinical trials before regulatory authority approval.

From an epidemiological perspective, C. culminatus envenoming in humans is likely to occur regularly in the rural environments but is seldom documented due to poor epidemiology being a broad medical issue in such remote communities (Rebolledo, personal communication, January 2020), whereas C. simus (i.e., C. mictlantecuhtli + C. ehecatl + C. simus) is responsible for the majority of rattlesnake bite episodes in several Mexican states and Central American countries $(14,158)$. As populations centers spread into the remote areas occupied by $C$. culminatus, envenomations may increase in frequency. In addition, this species is sought after in the exotic pet trade and thus bites from captive C. culminatus individuals in the private reptile keeping sector may result in significant medical complications not neutralizable by available antivenoms, especially in countries where the species is not native. This species is therefore of potential clinical concern and we recommend further research on optimal treatments for its envenoming.

\section{Conclusion}

This study reports the first occurrence of true procoagulant venom activity in Mexican Neotropical rattlesnakes for the species Crotalus culminatus, especially in early life stages. This went largely undetected in previous studies due to the lack of $\mathrm{Ca}^{2+}$ and phospholipids in plasma clotting assays resulting in experimental conditions lacking physiological venom requirements for functional activity. The poor efficiency of one of the main Mexican antivenom products against this action highlights the need to include a wide array of snake species and life-stages in antivenom immunizing mixtures. The metalloprotease inhibitor Prinomastat however was highly effective in neutralizing the procoagulant venom activity in C. culminatus, further validating the use of small molecule inhibitors as adjunct treatment for snakebite despite DMPS performing poorly in comparison. Overall, we hope our results will contribute to the evidence-based design of clinical management strategies for rattlesnake envenoming in Mexico and emphasize the importance of natural history and evolutionary research on rattlesnakes and their venom.

\section{REFERENCES}

1. Williams DJ, Faiz MA, Abela-Ridder B, Ainsworth S, Bulfone TC, Nickerson $\mathrm{AD}$, et al. Strategy for a globally coordinated response to a priority neglected tropical disease: snakebite envenoming. PLoS Negl Trop Dis. (2019) 13:e0007059. doi: 10.1371/journal.pntd.00 07059

2. Fry BG. Snakebite: when the human touch becomes a bad touch. Toxins. (2018) 10:170. doi: 10.3390/toxins10040170

3. Harrison RA, Hargreaves A, Wagstaff SC, Faragher B, Lalloo DG. Snake envenoming: a disease of poverty. PLoS Negl Trop Dis. (2009) 3:e569. doi: 10.1371/journal.pntd.0000569

4. Gutiérrez JM, León G, Burnouf T. Antivenoms for the treatment of snakebite envenomings: the road ahead. Biologicals. (2011) 39:129-42. doi: 10.1016/j.biologicals.2011.02.005

\section{DATA AVAILABILITY STATEMENT}

The raw data supporting the conclusions of this article will be made available by the authors, without undue reservation.

\section{ETHICS STATEMENT}

The studies involving human participants were reviewed and approved by Human plasma was sourced from surplus supplies from the Australian Red Cross under Human Ethics Approval \#2016000256. Written informed consent for participation was not required for this study in accordance with the national legislation and the institutional requirements. The animal study was reviewed and approved by Rhinella marina plasma was obtained under the University of Queensland Animal Ethics approval SBS/019/14/ARC.

\section{AUTHOR CONTRIBUTIONS}

LS, CZ, AC, and CR performed the experiments. LS, AC, and CR analyzed the data. EN-C, MB-V, and AA provided the venoms. $\mathrm{BF}$ designed the study. LS, CZ, and BF wrote the manuscript. All authors proof-read and revised the manuscript prior to submission.

\section{FUNDING}

BF was funded by the Australian Research Council Discovery Project DP190100304. LS was funded by a LUSTRA+ scholarship and a Leiden University Funds (LUF) grant (reference number: L19104-1-45).

\section{ACKNOWLEDGMENTS}

We thank Pablo Berea (OCTOLAB) and Israel López Cortes for their help in obtaining venom samples.

\section{SUPPLEMENTARY MATERIAL}

The Supplementary Material for this article can be found online at: https://www.frontiersin.org/articles/10.3389/fimmu. 2021.612846/full\#supplementary-material

5. Alirol E, Lechevalier P, Zamatto F, Chappuis F, Alcoba G, Potet J. Antivenoms for snakebite envenoming: what is in the research pipeline? PLoS Negl Trop Dis. (2015) 9:e0003896. doi: 10.1371/journal.pntd.0003896

6. Habib AG, Brown NI. The snakebite problem and antivenom crisis from a health-economic perspective. Toxicon. (2018) 150:115-23. doi: 10.1016/j.toxicon.2018.05.009

7. Longbottom J, Shearer FM, Devine M, Alcoba G, Chappuis F, Weiss DJ, et al. Vulnerability to snakebite envenoming: a global mapping of hotspots. Lancet. (2018) 392:673-84. doi: 10.1016/S0140-6736(18) 31224-8

8. Gutiérrez JM, Williams D, Fan HW, Warrell DA. Snakebite envenoming from a global perspective: towards an integrated approach. Toxicon. (2010) 56:1223-35. doi: 10.1016/j.toxicon.2009.11.020

9. Bénard-Valle M, Neri-Castro EE, Fry BG, Boyer L, Cochran C, Alam M, et al. Antivenom research and development. In: Fry BG, editor. Venomous Reptiles 
and Their Toxins: Evolution, Pathophysiology, and Biodiscovery. New York, NY: Oxford University Press (2015). p. 61-72.

10. Klauber LM. Rattlesnakes: Their Habits, Life Histories, and Influence on Mankind. Berkeley, CA: University of California Press (1972).

11. Langley, RL. Animal bites and stings reported by United States Poison Control Centers:2001-2005. Wilderness Environ Med. (2008) 19:7-14. doi: 10.1580/07-WEME-OR-111.1

12. Seifert SA, Boyer LV, Benson BE, Rogers JJ. AAPCC database characterization of native U.S. venomous snake exposures:2001-2005. Clin Toxicol. (2009) 47:327-35. doi: 10.1080/15563650902870277

13. Ruha AM, Kleinschmidt KC, Greene S, Spyres MB, Brent J, Wax P, et al. The epidemiology, clinical course, and management of snakebites in the North American Snakebite Registry. J Med Toxicol. (2017) 13:309-20. doi: 10.1007/s13181-017-0633-5

14. Gutiérrez JM. Reducing the impact of snakebite envenoming in latin America and the Caribbean: achievements and challenges ahead. Trans $R$ Soc Trop Med Hyg. (2014) 108: 530-7. doi: 10.1093/trstmh/tru102

15. Chippaux JP. Incidence and mortality due to snakebite in the Americas. Plos Neg Trop Dis. (2017) 11:e0005662. doi: 10.1371/journal.pntd.0005662

16. Beaman KR, Hayes WK. Rattlesnakes: research trends and annotated checklist. In Hayes WK, Beaman KR, Cardwell MD, Bush SP, editors. The Biology of Rattlesnakes. Loma Linda, CA: Loma Linda University Press (2008). p. 5-16.

17. Castoe TA, Spencer CL, Parkinson CL. Phylogeographic structure and historical demography of the western diamondback rattlesnake (Crotalus atrox): a perspective on North American desert biogeography. Mol Phylogenet Evol. (2007) 42:193-212. doi: 10.1016/j.ympev.2006.07.002

18. Adrian Quijada-Mascareñas J, Ferguson JE, Pook CE, Salomão MDG, Thorpe RS, Wüster W. Phylogeographic patterns of trans-Amazonian vicariants and Amazonian biogeography: the Neotropical rattlesnake (Crotalus durissus complex) as an example. J Biogeogr. (2007) 34:1296-312. doi: $10.1111 / j .1365-2699.2007 .01707 . x$

19. Ashton KG, Queiroz A De. Molecular systematics of the western rattlesnake, Crotalus viridis (Viperidae), with comments on the utility of the D-loop in phylogenetic studies of snakes. Mol Phylogenet Evol. (2001) 21:176-89. doi: $10.1006 / \mathrm{mpev} .2001 .1013$

20. Giorgianni MW, Dowell NL, Griffin S, Kassner VA, Selegue JE, Carroll SB. The origin and diversification of a novel protein family in venomous snakes. Proc Natl Acad Sci USA. (2020) 117:10911-920. doi: 10.1073/pnas.1920011117

21. Schuett GW, Clark RW, Repp RA, Amarello M, Smith CF, Greene HW. Social behavior of rattlesnakes: a shifting paradigm. In: Schuett GW, Feldner MJ, Smith CF, Reiserer RS, editors. Rattlesnakes of Arizona. Rodeo, NM: ECO Publishing (2016). p. 161-242.

22. Blair C, Sánchez-Ramírez S. Diversity-dependent cladogenesis throughout western Mexico: evolutionary biogeography of rattlesnakes (Viperidae: Crotalinae: Crotalus and Sistrurus). Mol Phylogenet Evol. (2016) 97:145-54. doi: 10.1016/j.ympev.2015.12.020

23. Campell JA, Lamar WW, Brodie ED. The Venomous Reptiles of the Western Hemisphere. Ithaca, NY: Comstock Publishing Associates (2004).

24. Heimes P. Snakes of Mexico. Frankfurt am Main: Edition Chimaira (2016).

25. Wüster W, Ferguson JE, Quijada-Mascareñas JA, Pook CE, Salomão MDG, Thorpe RS. Tracing an invasion: landbridges, refugia, and the phylogeography of the Neotropical rattlesnake (Serpentes: Viperidae: Crotalus durissus). Mol Ecol. (2005) 14:1095-108. doi: 10.1111/j.1365-294X.2005.02471.x

26. Carbajál-Márquez RA, Cedeño-Vázquez JR, Martínez-Arce A, Neri-Castro E, Machkour- M'Rabet SC. Accessing cryptic diversity in Neotropical rattlesnakes (Serpentes: Viperidae: Crotalus) with the description of two new species. Zootaxa. (2020) 4729:451-81. doi: 10.11646/zootaxa. 4729.4.1

27. Anderson CG, Greenbaum E. Phylogeography of Northern populations of the black-tailed rattlesnake (Crotalus molossus Baird And Girard, 1853), With the Revalidation of C. ornatus Hallowell, 1854. Herpetol Monogr. (2012) 26:19-57. doi: 10.1655/HERPMONOGRAPHS-D-11-00012.1

28. Sotelo N. Review of treatment and complications in 79 children with rattlesnake bite. Clin Pediatr. (2008) 47:483-9. doi: $10.1177 / 0009922807311734$
29. Yañez-Arenas C, Peterson AT, Mokondoko P, Rojas-Soto O, Martínez-Meyer E. The use of ecological niche modeling to infer potential risk areas of snakebite in the Mexican State of Veracruz. PLoS ONE. (2014) 9:e100957. doi: 10.1371/journal.pone.0100957

30. Yañez-Arenas C, Yañez-Arenas A, Martínez-Ortíz D. Panorama epidemiológico de las mordeduras por serpiente venenosa en el estado de Yucatán, México (2003-2012). Gac Med Mex. (2016) 152:568-74.

31. Arnaud G, Saucedo AC, Park B, Fumero S, Pozas-ocampo F. Comprendiendo el veneno de las serpientes de cascabel: componentes, efectos y uso potencial. Áreas Nat Protegidas Scripta. (2019) 5:39-56. doi: 10.18242/anpscripta.2019.05.05.02.0003

32. Sánchez M, Solano G, Vargas M, Reta-Mares F, Neri-Castro É, Alagón A, et al. Toxicological profile of medically relevant Crotalus species from Mexico and their neutralization by a Crotalus basiliscus/Bothrops asper antivenom. Toxicon. (2020) 179:92-100. doi: 10.1016/j.toxicon.2020.03.006

33. Calvete JJ, Sanz L, Cid P, De La Torre P, Flores-Díaz M, Dos Santos MC, et al. Snake venomics of the Central American Rattlesnake Crotalus simus and the South American Crotalus durissus complex points to neurotoxicity as an adaptive paedomorphic trend along Crotalus dispersal in South America. J Proteome Res. (2010) 9:528-44. doi: 10.1021/pr9008749

34. Boldrini-França J, Corrêa-Netto C, Silva MMS, Rodrigues RS, De La Torre P, Pérez A, et al. Snake venomics and antivenomics of Crotalus durissus subspecies from Brazil: assessment of geographic variation and its implication on snakebite management. J Proteomics. (2010) 73:1758-76. doi: 10.1016/j.jprot.2010.06.001

35. Neri-Castro EE, Hernández-Dávila A, Olvera-Rodríguez A, Cardoso-Torres $H$, Bénard-Valle M, Bastiaans E, et al. Detection and quantification of a $\beta$ neurotoxin (crotoxin homologs) in the venom of the rattlesnakes Crotalus simus, C. culminatus and C. tzabcan from Mexico. Toxicon X. (2019) 2:100007. doi: 10.1016/j.toxcx.2019.100007

36. Francischetti IMB, Gombarovits MEC, Valenzuela JG, Carlini CR, Guimarães JA. Intraspecific variation in the venoms of the South American rattlesnake (Crotalus durissus terrificus). Comp Biochem Physiol C Pharmacol Toxicol Endocrinol. (2000) 127:23-36. doi: 10.1016/S0742-8413(00)00129-8

37. Dos-Santos MC, Assis EB, Moreira TD, Pinheiro J, Fortes-Dias CL. Individual venom variability in Crotalus durissus ruruima snakes, a subspecies of Crotalus durissus from the Amazonian region. Toxicon. (2005) 46:958-61. doi: 10.1016/j.toxicon.2005.06.008

38. Mackessy SP. Venom composition in rattlesnakes: trends and biological significance. In: Hayes WK, Beaman KR, Cardwell MD, Bush SP, editors. The Biology of Rattlesnakes. Loma Linda, CA: Loma Linda University Press (2008). p. 495-510.

39. Sartim MA, Souza CO, Diniz CRAF, da Fonseca VMB, Sousa LO, Peti $\mathrm{APF}$, et al. Crotoxin-induced mice lung impairment: role of nicotinic acetylcholine receptors and COX-derived prostanoids. Biomol. (2020) 10:794. doi: 10.3390/biom 10050794

40. Cavalcante WG, Noronha-Matos JB, Timóteo MA, Fontes MRM, Gallacci M, Correia-de-Sá P. Neuromuscular paralysis by the basic phospholipase $\mathrm{A}_{2}$ subunit of crotoxin from Crotalus durissus terrificus snake venom needs its acid chaperone to concurrently inhibit acetylcholine release and produce muscle blockage. Toxicol Appl Pharmacol. (2017) 334:8-17. doi: 10.1016/j.taap.2017.08.021

41. Brazil, OV. Pharmacology of crystalline crotoxin. II. Neuromuscular blocking action. Mem Inst Butantan. (1966) 33:981-92.

42. Dobson J, Yang DC, op den Brouw B, Cochran C, Huynh T, Kurrupu S, et al. Rattling the border wall: pathophysiological implications of functional and proteomic venom variation between Mexican and US subspecies of the desert rattlesnake Crotalus scutulatus. Comp Biochem Physiol Part C Toxicol Pharmacol. (2018) 205:62-9. doi: 10.1016/j.cbpc.2017.10.008

43. Saravia P, Rojas E, Arce V, Guevara C, López JC, Chaves E, et al. Geographic and ontogenic variability in the venom of the neotropical rattlesnake Crotalus durissus: pathophysiological and therapeutic implications. Rev Biol Trop. (2002) 337-46.

44. Neri-Castro EE, Lomonte B, del Carmen Gutiérrez M, Alagón A, Gutiérrez JM. Intraspecies variation in the venom of the rattlesnake Crotalus simus from Mexico: different expression of crotoxin results in highly variable toxicity in the venoms of three subspecies. J Proteomics. (2013) 87:103-21. doi: 10.1016/j.jprot.2013.05.024 
45. Durban J, Sanz L, Trevisan-Silva D, Neri-Castro E, Alagón A, Calvete JJ. Integrated venomics and venom gland transcriptome analysis of Juvenile and Adult Mexican Rattlesnakes Crotalus simus, C. tzabcan, and C. culminatus revealed miRNA-modulated ontogenetic shifts. J Proteome Res. (2017) 16:3370-90. doi: 10.1021/acs.jproteome.7b00414

46. Neri-Castro EE, Ponce-López R. Variación ontogénica en el veneno de Crotalus simus en México. Árido-Ciencia. (2018) 3:42-7.

47. Markland FS. Rattlesnake venom enzymes that interact with components of the hemostatic system. Toxin Rev. (1983) 2:119-60. doi: 10.3109/15569548309012695

48. Markland FS, Swenson S. Snake venom metalloproteinases. Toxicon. (2013) 62:3-18. doi: 10.1016/j.toxicon.2012.09.004

49. Gutiérrez JM, Escalante T, Rucavado A, Herrera C. Hemorrhage caused by snake venom metalloproteinases: a journey of discovery and understanding. Toxins. (2016) 8:93. doi: 10.3390/toxins8040093

50. Debono J, Bos MHA, Do MS, Fry BG. Clinical implications of coagulotoxic variations in Mamushi (Viperidae: Gloydius) snake venoms. Comp Biochem Physiol Part C Toxicol Pharmacol. (2019) 225: 108567. doi: 10.1016/j.cbpc.2019.108567

51. Debono J, Bos MHA, Nouwens A, Ge L, Frank N, Kwok HF, et al. Habu coagulotoxicity: clinical implications of the functional diversification of Protobothrops snake venoms upon blood clotting factors. Toxicol Vitr. (2019) 55:62-74. doi: 10.1016/j.tiv.2018.11.008

52. Debono J, Bos MHA, Frank N, Fry B. Clinical implications of differential antivenom efficacy in neutralising coagulotoxicity produced by venoms from species within the arboreal viperid snake genus Trimeresurus. Toxicol Lett. (2019) 316:35-48. doi: 10.1016/j.toxlet.2019. 09.003

53. Debono J, Bos MHA, Coimbra F, Ge L, Frank N, Kwok HF, et al. Basal but divergent: clinical implications of differential coagulotoxicity in a clade of Asian vipers. Toxicol Vitr. (2019) 58:195-206. doi: 10.1016/j.tiv.2019.03.038

54. Bourke LA, Youngman NJ, Zdenek CN, op den Brouw B, Violette A, Fourmy R, et al. Trimeresurus albolabris snakebite treatment implications arising from ontogenetic venom comparisons of anticoagulant function, and antivenom efficacy. Toxicol Lett. (2020) 327:2-8. doi: 10.1016/j.toxlet.2020.03.009

55. Chowdhury A, Zdenek CN, Dobson JS, Bourke LA, Soria R, Fry BG. Clinical implications of differential procoagulant toxicity of the Palearctic viperid genus Macrovipera, and the relative neutralization efficacy of antivenoms and enzyme inhibitors. Toxicol Lett. (2021) 340:77-88. doi: 10.1016/j.toxlet.2020.12.019

56. Rogalski A, Soerensen C, op den Brouw B, Lister C, Dashvesky D, Arbuckle $\mathrm{K}$, et al. Differential procoagulant effects of saw-scaled viper (Serpentes: Viperidae: Echis) snake venoms on human plasma and the narrow taxonomic ranges of antivenom efficacies. Toxicol Lett. (2017) 280:159-70. doi: 10.1016/j.toxlet.2017.08.020

57. Oulion B, Dobson JS, Zdenek CN, Arbuckle K, Lister C, Coimbra FCP, et al. Factor X activating Atractaspis snake venoms and the relative coagulotoxicity neutralising efficacy of African antivenoms. Toxicol Lett. (2018) 288:119-28. doi: 10.1016/j.toxlet.2018.02.020

58. Zdenek CN, Hay C, Arbuckle K, Jackson TNW, Bos MHA, op den Brouw $\mathrm{B}$, et al. Coagulotoxic effects by brown snake (Pseudonaja) and taipan (Oxyuranus) venoms, and the efficacy of a new antivenom. Toxicol Vitr. (2019) 58:97-109. doi: 10.1016/j.tiv.2019.03.031

59. Zdenek CN, den Brouw B op, Dashevsky D, Gloria A, Youngman NJ, Watson E, et al. Clinical implications of convergent procoagulant toxicity and differential antivenom efficacy in Australian elapid snake venoms. Toxicol Lett. (2019) 36:171-82. doi: 10.1016/j.toxlet.2019.08.014

60. Bonilla CA, Faith MR, Minton SA. l-Amino acid oxidase, phosphodiesterase, total protein and other properties of juvenile timber rattlesnake (C. $h$. horridus) venom at different stages of growth. Toxicon. (1973) 11:301-2. doi: 10.1016/0041-0101(73)90059-7

61. Reid HA, Theakston RDG. Changes in coagulation effects by venoms of Crotalus atrox as snakes age. Am J Trop Med Hyg. (1978) 27:1053-7. doi: 10.4269/ajtmh.1978.27.1053

62. Denson KWE, Russell FE, Almagro D, Bishop RC. Characterization of the coagulant activity of some snake venoms. Toxicon. (1972) 10:557-62. doi: 10.1016/0041-0101(72)90116-X
63. Suntravat M, Nuchprayoon I, Pérez JC. Comparative study of anticoagulant and procoagulant properties of 28 snake venoms from families Elapidae, Viperidae, and purified Russell's viper venom-factor X activator (RVV-X). Toxicon. (2010) 56:544-53. doi: 10.1016/j.toxicon.2010.05.012

64. Theakston RDG, Reid HA. Development of simple standard assay procedures for the characterization of snake venoms. Bull World Health Organ. (1983) 61:949.

65. Bevers EM, Williamson PL. Getting to the outer leaflet: physiology of phosphatidylserine exposure at the plasma membrane. Physiol Rev. (2016) 96:605-45. doi: 10.1152/physrev.00020.2015

66. van Dieijen GV, Tans G, van Rijn JV, Zwaal RF, Rosing J. Simple and rapid method to determine the binding of clotting factor $\mathrm{X}$ to phospholipids vesicles. Biochem. (1981) 20:7096-101. doi: 10.1021/bi00528a007

67. Marshall LR, Herrmann RP. Coagulant and anticoagulant actions of Australian snake venoms. Thromb Haemost. (1983) 50:707-11. doi: 10.1055/s-0038-1665292

68. Tans G, Govers-Riemslag JWP, van Rihn JL, Rosing J. Purification and properties of a prothrombin activator from the venom of Notechis scutatus scutatus. J Biol Chem. (1985) 260:9366-72. doi: 10.1016/S0021-9258(17)39373-0

69. Speijer H, Govers-Riemslag JWP, Zwaal RFA, Rosing J. Prothrombin activation by an activator from the venom of Oxyuranus scutellatus (Taipan snake). J Biol Chem. (1986) 261:13258-67. doi: 10.1016/S0021-9258(18)69299-3

70. Nakagaki T, Lin P, Kisiel W. Activation of human Factor VII by the prothrombin activator from the venom of Oxyuranus scutellatus (Taipan snake). Thromb Res. (1992) 65:105-16. doi: 10.1016/0049-3848(92)90230-8

71. Rosing J, Tans G. Structural and functional properties of snake venom prothrombin activators. Toxicon. (1992) 30:1515-27. doi: 10.1016/0041-0101(92)90023-X

72. Rao V, Kini RM. Pseutarin C, a prothrombin activator from Pseudonaja textilis venom: its structural and functional similarity to mammalian coagulation factor Xa-Va complex. Thromb Haemost. (2002) 88:611-9. doi: 10.1055/s-0037-1613264

73. Rao V, Joseph VS, Kini RM. Group D prothrombin activators from snake venom are structural homologues of mammalian blood coagulation Factor Xa. Biochem J. (2003) 369:635-42. doi: 10.1042/bj20020889

74. Debono J, Dobson J, Casewell NR, Romilio A, Li B, Kurniawan N, et al. Coagulating colubrids: evolutionary, pathophysiological and biodiscovery implications of venom variations between boomslang (Dispholidus typus) and twig snake (Thelotornis mossambicanus). Toxins. (2017) 9:171. doi: 10.3390/toxins9050171

75. Dobson JS, Zdenek CN, Hay C, Violette A, Fourmy R, Cochran C, et al. Varanid lizard venoms disrupt the clotting ability of human fibrinogen through destructive cleavage. Toxins. (2019) 11:255. doi: 10.3390/toxins11050255

76. Youngman NJ, Debono J, Dobson JS, Zdenek CN, Harris RJ, den Brouw B op, et al. Venomous landmines: clinical implications of extreme coagulotoxic diversification and differential neutralization by antivenom of venoms within the viperid snake genus Bitis. Toxins. (2019) 11:422. doi: 10.3390/toxins11070422

77. O'Leary MA, Isbister GK. A turbidimetric assay for the measurement of clotting times of procoagulant venoms in plasma. J Pharmacol Toxicol Methods. (2010) 61:27-31. doi: 10.1016/j.vascn.2009.06.004

78. Isbister GK, Woods D, Alley S, O’Leary MA, Seldon M, Lincz LF. Endogenous thrombin potential as a novel method for the characterization of procoagulant snake venoms and the efficacy of antivenom. Toxicon. (2010) 56: 75-85. doi: 10.1016/j.toxicon.2010.03.013

79. Vargas M, Segura A, Herrera M, Villalta M, Estrada R, Cerdas $M$, et al. Preclinical evaluation of caprylic acid-fractionated igg antivenom for the treatment of taipan (Oxyuranus scutellatus) envenoming in Papua New Guinea. PLoS Negl Trop Dis. (2011) 5:e1144. doi: 10.1371/journal.pntd.0001144

80. Bernardoni JL, Sousa LF, Wermelinger LS, Lopes AS, Prezoto BC, Serrano SMT, et al. Functional variability of snake venom metalloproteinases: adaptive advantages in targeting different prey and implications for human envenoming. PLoS ONE. (2014) 9:e109651. doi: 10.1371/journal.pone.0109651 
81. Oguiura N, Kapronezai J, Ribeiro T, Rocha MMT, Medeiros CR, Marcelino $\mathrm{JR}$, et al. An alternative micromethod to access the procoagulant activity of Bothrops jararaca venom and the efficacy of antivenom. Toxicon. (2014) 90:148-54. doi: 10.1016/j.toxicon.2014.08.004

82. Tan NH, Fung SY, Tan KY, Yap MKK, Gnanathasan CA, Tan CH. Functional venomics of the Sri Lankan Russell's viper (Daboia russelii) and its toxinological correlations. J Proteomics. (2015) 128:403-23. doi: 10.1016/j.jprot.2015.08.017

83. Tan KY, Tan NH, Tan CH. Venom proteomics and antivenom neutralization for the Chinese eastern Russell's viper, Daboia siamensis from Guangxi and Taiwan. Sci Rep. (2018) 8:1-14. doi: 10.1038/s41598-018-25955-y

84. Nielsen VG, Boyer L V. Iron and carbon monoxide attenuate degradation of plasmatic coagulation by Crotalus atrox venom. Blood Coagul Fibrinolysis. (2016) 27:506-10. doi: 10.1097/MBC.0000000000000440

85. Nielsen VG. Iron and carbon monoxide prevent degradation of plasmatic coagulation by thrombin-like activity in rattlesnake venom. Hum Exp Toxicol. (2016) 35:1-7. doi: 10.1177/0960327115621366

86. Nielsen VG. Ruthenium, not carbon monoxide, inhibits the procoagulant activity of Atheris, Echis, and Pseudonaja venoms. Int J Mol Sci. (2020) 21:1-12. doi: 10.3390/ijms21082970

87. Still K, Nandlal R, Slagboom J, Somsen G, Casewell N, Kool J. Multipurpose HTS coagulation analysis: assay development and assessment of coagulopathic snake venoms. Toxins. (2017) 9:1-16. doi: 10.3390/toxins9120382

88. Faisal T, Tan KY, Sim SM, Quraishi N, Tan NH, Tan CH. Proteomics, functional characterization and antivenom neutralization of the venom of Pakistani Russell's viper (Daboia russelii) from the wild. J Proteomics. (2018) 183:1-13. doi: 10.1016/j.jprot.2018.05.003

89. Nielsen VG, Frank N. Differential heme-mediated modulation of Deinagkistrodon, Dispholidus, Protobothrops and Pseudonaja hemotoxic venom activity in human plasma. BioMetals. (2018) 31:951-9. doi: 10.1007/s10534-018-0137-z

90. Chaisakul J, Alsolaiss J, Charoenpitakchai M, Wiwatwarayos K, Sookprasert $\mathrm{N}$, Harrison RA, et al. Evaluation of the geographical utility of Eastern Russell's viper (Daboia siamensis) antivenom from Thailand and an assessment of its protective effects against venom-induced nephrotoxicity. PLoS Negl Trop Dis. (2019) 13:1-27. doi: 10.1371/journal.pntd.00 07338

91. Xie C, Slagboom J, Albulescu LO, Bruyneel B, Still KBM, Vonk FJ, et al. Antivenom neutralization of coagulopathic snake venom toxins assessed by bioactivity profiling using nanofractionation analytics. Toxins. (2020) 12:53. doi: 10.3390/toxins12010053

92. Slagboom J, Mladić M, Xie C, Kazandjian TD, Vonk F, Somsen GW, et al. High throughput screening and identification of coagulopathic snake venom proteins and peptides using nanofractionation and proteomics approaches. PLoS Negl Trop Dis. (2020) 14:e0007802. doi: 10.1371/journal.pntd.00 07802

93. Sanz L, Quesada-Bernat S, Pérez A, De Morais-Zani K, Sant'Anna SS, Hatakeyama DM, et al. Danger in the Canopy. Comparative proteomics and bioactivities of the venoms of the South American palm pit viper Bothrops bilineatus subspecies bilineatus and smaragdinus and antivenomics of $B$. b. bilineatus (Rondônia) venom against the Brazilian Pentabo. J Proteome Res. (2020) 19:3518-32. doi: 10.1021/acs.jproteome.0c 00337

94. Borja M, Neri-Castro EE, Pérez-Morales R, Strickland JL, Ponce-López $\mathrm{R}$, Parkinson $\mathrm{CL}$, et al. Ontogenetic change in the venom of mexican blacktailed rattlesnakes (Crotalus molossus nigrescens). Toxins. (2018) 10:127. doi: 10.3390/toxins10120501

95. Williams V, White J, Mirtschin PJ. Comparative study on the procoagulant from the venom of Australian brown snakes (Elapidae; Pseudonaja spp.). Toxicon. (1994) 32:453-9. doi: 10.1016/0041-0101(94)90297-6

96. Tan CH, Liew JL, Tan KY, Tan NH. Assessing SABU (Serum Anti Bisa Ular), the sole Indonesian antivenom: a proteomic analysis and neutralization efficacy study. Sci Rep. (2016) 6:1-10. doi: 10.1038/srep37299

97. Tan CH, Tan KY, Ng TS, Quah ESH, Ismail AK, Khomvilai S, et al. Venomics of Trimeresurus (Popeia) nebularis, the cameron highlands pit viper from Malaysia: insights into venom proteome, toxicity and neutralization of antivenom. Toxins. (2019) 11:1-18. doi: 10.3390/toxins11020095
98. Salazar-Valenzuela D, Mora-Obando D, Fernández ML, Loaiza-Lange A, Gibbs HL, Lomonte B. Proteomic and toxicological profiling of the venom of Bothrocophias campbelli, a pitviper species from Ecuador and Colombia. Toxicon. (2014) 90:15-25. doi: 10.1016/j.toxicon.2014.07.012

99. Nielsen VG, Boyer LV, Redford DT, Ford P. Thrombelastographic characterization of the thrombin-like activity of Crotalus simus and Bothrops asper venoms. Blood Coagul Fibrinolysis. (2017) 28:211-7. doi: 10.1097/MBC.0000000000000577

100. Farias IB de, Morais-Zani K de, Serino-Silva C, Sant'Anna SS, Rocha MMT d, Grego KF, et al. Functional and proteomic comparison of Bothrops jararaca venom from captive specimens and the Brazilian Bothropic Reference Venom. J Proteomics. (2018) 174:36-46. doi: 10.1016/j.jprot.2017.12.008

101. Resiere D, Arias AS, Villalta M, Rucavado A, Brouste Y, Cabié A, et al. Preclinical evaluation of the neutralizing ability of a monospecific antivenom for the treatment of envenomings by Bothrops lanceolatus in Martinique. Toxicon. (2018) 148:50-5. doi: 10.1016/j.toxicon.2018.04.010

102. Ainsworth S, Slagboom J, Alomran N, Pla D, Alhamdi Y, King SI, et al. The paraspecific neutralisation of snake venom induced coagulopathy by antivenoms. Commun Biol. (2018) 1:1-14. doi: 10.1038/s42003-018-0039-1

103. Tang ELH, Tan NH, Fung SY, Tan CH. Comparative proteomes, immunoreactivities and neutralization of procoagulant activities of Calloselasma rhodostoma (Malayan pit viper) venoms from four regions in Southeast Asia. Toxicon. (2019) 169:91-102. doi: 10.1016/j.toxicon.2019.08.004

104. Pereañez JA, Preciado LM, Fernández J, Camacho E, Lomonte B, Castro F, et al. Snake venomics, experimental toxic activities and clinical characteristics of human envenoming by Bothrocophias myersi (Serpentes: Viperidae) from Colombia. J Proteomics. (2020) 220:1-7. doi: 10.1016/j.jprot.2020.103758

105. Howes JM, Theakston RDG, Laing GD. Neutralization of the haemorrhagic activities of viperine snake venoms and venom metalloproteinases using synthetic peptide inhibitors and chelators. Toxicon. (2007) 49:734-9. doi: 10.1016/j.toxicon.2006.11.020

106. Albulescu LO, Hale MS, Ainsworth S, Alsolaiss J, Crittenden E, Calvete JJ, et al. Preclinical validation of a repurposed metal chelator as an earlyintervention therapeutic for hemotoxic snakebite. Sci Transl Med. (2020) 12:542. doi: 10.1126/scitranslmed.aay8314

107. Lister C, Arbuckle K, Jackson TNW, Debono J, Zdenek CN, Dashevsky D, et al. Catch a tiger snake by its tail: differential toxicity, co-factor dependence and antivenom efficacy in a procoagulant clade of Australian venomous snakes. Comp Biochem Physiol Part C Toxicol Pharmacol. (2017) 202:39-54. doi: 10.1016/j.cbpc.2017.07.005

108. Al-Abdulla I, Casewell NR, Landon J. Long-term physicochemical and immunological stability of a liquid formulated intact ovine immunoglobulin-based antivenom. Toxicon. (2013) 64:38-42. doi: 10.1016/j.toxicon.2012.12.022

109. O’Leary MA, Kornhauser RS, Hodgson WC, Isbister GK. An examination of the activity of expired and mistreated commercial Australian antivenoms. Trans R Soc Trop Med Hyg. (2009) 103:937-42. doi: 10.1016/j.trstmh.2008.11.011

110. Cipriani V, Debono J, Goldenberg J, Jackson TNW, Arbuckle K, Dobson J, et al. Correlation between ontogenetic dietary shifts and venom variation in Australian brown snakes (Pseudonaja). Comp Biochem Physiol Part C Toxicol Pharmacol. (2017) 187:53-60. doi: 10.1016/j.cbpc.2017.04.007

111. Yamada D, Sekiya F, Morita T. Prothrombin and factor X activator activities in the venoms of Viperidae snakes. Toxicon. (1997) 35:1581-9. doi: 10.1016/S0041-0101(97)00043-3

112. Neri-Castro EE, Bénard-Valle M, Gil G, Borja M, López de León J, Alagón A. Serpientes venenosas en México: revisión al estudio de los venenos, los antivenenos y la epidemiología. Revista Latinoamericana Herpetol. (2020) 3:5-22.

113. Sousa LF, Zdenek CN, Dobson JS, den Brouw B op, Coimbra FCP, Gillett A, et al. Coagulotoxicity of Bothrops (lancehead pit-vipers) venoms from Brazil: differential biochemistry and antivenom efficacy resulting from prey-driven venom variation. Toxins. (2018) 10:10. doi: 10.3390/toxins101 00411

114. Youngman NJ, Chowdhury A, Zdenek CN, Coster K, Sundman E, Braun R, et al. Utilising venom activity to infer dietary composition of the Kenyan 
horned viper (Bitis worthingtoni). Comp Biochem Phys C. (2020) 240:108921. doi: 10.1016/j.cbpc.2020.108921

115. Rael ED, Rivas JZ, Chen T, Maddux N, Huizar E, Lieb CS. Differences in fibrinolysis and complement inactivation by venom from different northern blacktailed rattlesnakes (Crotalus molossus molossus). Toxicon. (1997) 35:505-13. doi: 10.1016/S0041-0101(96) 00139-0

116. Macias-Rodríguez EF, Martínez-Martínez A, Gatica-Colima A, BojórquezRangel G, Plenge-Tellechea LF. Análisis comparativo de la actividad hemolítica entre las subespecies Crotalus molossus y Crotalus molossus nigrescens. Rev Bio Ciencias. (2014) 2:302-12. doi: 10.15741/revbio.02.04.08

117. Kini RM. Anticoagulant proteins from snake venoms: structure, function, and mechanism. Biochem J. (2006) 397:377-87. doi: 10.1042/BJ20060302

118. Teng CM, Wang JP, Huang TF, Liau MY. Effects of venom proteases on peptide chromogenic substrates and bovine prothrombin. Toxicon. (1989) 27:161-7. doi: 10.1016/0041-0101(89)90129-3

119. Wang WJ, Shih $\mathrm{CH}$, Huang TF. A novel P-I class metalloproteinase with broad substrate-cleaving activity, agkislysin, from Agkistrodon acutus venom. Biochem Biophys Res Commun. (2004) 324:224-30. doi: 10.1016/j.bbrc.2004.09.031

120. Pirkle H, Markland FS, Theodor I. Thrombin-like enzymes of snake venoms: actions onprothrombin. Thromb Res. (1976). doi: 10.1016/0049-3848(76)90167-5

121. Mackessy SP. Venom ontogeny in the Pacific rattlesnakes Crotalus viridis helleri and C. v. oreganus. Copeia. (1988) 1:92-101. doi: 10.2307/14 45927

122. Mackessy SP, Williams K, Ashton KG. Ontogenetic variation in venom composition and diet of Crotalus oreganus concolor: a case of venom paedomorphosis? Copeia. (2003) 2003:769-82. doi: 10.1643/HA03-037.1

123. Gibbs HL, Sanz L, Chiucchi JE, Farrell TM, Calvete JJ. Proteomic analysis of ontogenetic and diet-related changes in venom composition of juvenile and adult Dusky Pigmy rattlesnakes (Sistrurus miliarius barbouri). J Proteomics. (2011) 74:2169-79. doi: 10.1016/j.jprot.2011.06.013

124. Mackessy SP, Leroy J, Mociño-Deloya E, Setser K, Bryson RW, Saviola AJ. Venom ontogeny in the mexican lance-headed rattlesnake (Crotalus polystictus). Toxins. (2018) 10:271. doi: 10.3390/toxins10070271

125. Monteiro WM, Contreras-Bernal JC, Bisneto PF, Sachett J, Mendonça da Silva I, Lacerda M, et al. Bothrops atrox, the most important snake involved in human envenomings in the Amazon: how venomics contributes to the knowledge of snake biology and clinical toxinology. Toxicon X. (2020) 6:100037. doi: 10.1016/j.toxcx.2020.100037

126. Carbajal-Márquez RA, Cedeño-Vázquez JR, González-Solís D, Martins M. Diet and feeding ecology of Crotalus tzabcan (Serpentes: Viperidae). South Am J Herpetol. (2020) 15:9-19. doi: 10.2994/SAJH-D-17-00081.1

127. Carbajal-Márquez RA, Cedeño-Vázquez JR, Martins M, Köhler G. Life history, activity pattern, and morphology of Crotalus tzabcan Klauber, 1952 (Serpentes: Viperidae). Herpetol Conserv Biol. (2020) 15:228-37.

128. Sant'Anna SS, Abe AS. Diet of the rattlesnake Crotalus durissus in southeastern Brazil (Serpentes, Viperidae). Stud Neotrop Fauna Environ. (2007) 42:169-74. doi: 10.1080/01650520601148313

129. Hoyos MA, Almeida-Santos SM. The South-American rattlesnake Crotalus durissus: feeding ecology in the central region of Brazil. Biota Neotrop. (2016) 16:3. doi: 10.1590/1676-0611-BN-2014-0027

130. Conant R, Armstrong BL, Murphy JB. The Natural History of Mexican Rattlesnakes. Lawrence, KS: Natural History Museum, University of Kansas (1979).

131. Woolrich-Piña GA, Padilla GE, DeSantis DL, Johnson JD, Mata-Silva V, Wilson LD. The herpetofauna of Puebla, Mexico: composition, distribution, and conservation status. Mesoamerican Herpetol. (2017) 4:791-884.

132. Casewell NR, Sunagar K, Takacs Z, Calvete JJ, Jackson TNW, Fry BG. Snake venom metalloprotease enzymes. In: Fry BG, editor. Venomous Reptiles and Their Toxins: Evolution, Pathophysiology and Biodiscovery. New York, NY: Oxford University Press (2015). p. 347-63.

133. LaBonte JP, Welch JC, Suarez RK. Digestive performance in neonatal Southern Pacific rattlesnakes (Crotalus oreganus helleri). Can J Zool. (2011) 89:705-13. doi: 10.1139/z11-034

134. Margres MJ, Wray KP, Seavy M, McGivern JJ, Sanader D, Rokyta DR. Phenotypic integration in the feeding system of the eastern diamondback rattlesnake (Crotalus adamanteus). Mol Ecol. (2015) 24:340520. doi: $10.1111 /$ mec. 13240

135. Neri-Castro E, Bénard-Valle M, Paniagua D, Boyer LV, Possani LD, López-Casillas F, et al. Neotropical rattlesnake (Crotalus simus) venom pharmacokinetics in lymph and blood using and ovine model. Toxins. (2020) 12:455. doi: 10.3390/toxins12070455

136. Bagoly Z, Koncz Z, Hársfalvi J, Muszbek, L. Factor XIII, clot structure, thrombosis. Thromb Res. (2012) 129:382-7. doi: 10.1016/j.thromres.2011.11.040

137. Collet J, Park D, Lesty C, Soria J, Soria C, Montalescot G, et al. Influence of fibrin network conformation and fibrin fiber diameter on fibrinolysis speed. Arterioscler Thromb Vasc Biol. (2000) 20:1354-61. doi: 10.1161/01.ATV.20.5.1354

138. Koh CY, Kini RM. From snake venom toxins to therapeutics-cardiovascular examples. Toxicon. (2012) 59:497-506. doi: 10.1016/j.toxicon.2011. 03.017

139. Longstaff C, Kolev K. Basic mechanisms and regulation of fibrinolysis. $J$ Thromb Haemost. (2015) 13:S98-105. doi: 10.1111/jth.12935

140. Ryan EA, Mockros LF, Weisel JW, Lorand L. Structural origins of fibrin clot rheology. Biophys J. (1999) 77:2813-26. doi: 10.1016/S0006-3495(99)77113-4

141. Wolberg, AS. Thrombin generation and fibrin clot structure. Blood Rev. (2007) 21:131-42. doi: 10.1016/j.blre.2006.11.001

142. Markland FS. Snake venoms and the hemostatic system. Toxicon. (1998) 36:1749-800. doi: 10.1016/S0041-0101(98)00126-3

143. Retzios AD, Markland FS. Purification, characterization, and cleavage sites of three fibrinolytic enzymes from the venom of Crotalus basiliscus basiliscus. Biochem. (1992) 31:4547-57. doi: 10.1021/bi00134a003

144. Sánchez EF, Richardson M, Gremski LH, Veiga SS, Yarleque A, Niland $S$, et al. A novel fibrinolytic metalloproteinase, barnettlysin-I from Bothrops barnetti (Barnett's pitviper) snake venom with anti-platelet properties. Biochim Biophys Acta Gen Subjects. (2016) 1860:542-56. doi: 10.1016/j.bbagen.2015.12.021

145. Sachett JDAG, da Silva AM, Dantas AWCB, Dantas TR, Colombini M, da Silva AMM, et al. Cerebrovascular accidents related to snakebites in the Amazon-two case reports. Wild Environ Med. (2020) 31:337-43. doi: $10.1016 /$ j.wem.2020.04.009

146. de Oliveira SS, Freitas-de-Sousa LA, Alves EC, de Lima Ferreira LC, da Silva IM, de Lacerda MVG, et al. Fatal stroke after Bothrops snakebite in the Amazonas state, Brazil: a case report. Toxicon. (2017) 138:102-6. doi: 10.1016/j.toxicon.2017.08.021

147. Isbister GK, Scorgie FE, O'Leary MA, Seldon M, Brown SGA, Lincz LF. Factor deficiencies in venom-induced consumption coagulopathy resulting from Australian elapid envenomation: Australian Snakebite Project (ASP-10). J Thromb Haemost. (2010) 8:2504-13. doi: 10.1111/j.1538-7836.2010.04050.x

148. Maduwage K, Isbister GK. Current treatment for venom-induced consumption coagulopathy resulting from snakebite. PLoS Negl Trop Dis. (2014) 8:e3220. doi: 10.1371/journal.pntd.0003220

149. Ponce-López R, Neri-Castro E, Borja M, Strickland JL, Alagón A. Neutralizing potency and immunochemical evaluation of an antiCrotalus mictlantecuhtli experimental serum. Toxicon. (2020) 187:171-80. doi: $10.1016 /$ j.toxicon.2020.08.026

150. Segura Á, Herrera M, Reta Mares F, Jaime C, Sánchez A, Vargas $\mathrm{M}$, et al. Proteomic, toxicological and immunogenic characterization of Mexican west-coast rattlesnake (Crotalus basiliscus) venom and its immunological relatedness with the venom of Central American rattlesnake (Crotalus simus). J Proteomics. (2017) 158:62-72. doi: 10.1016/j.jprot.2017. 02.015

151. Jackson TNW, Koludarov I, Ali SA, Dobson J, Zdenek CN, Dashevsky $D$, et al. Rapid radiations and the race to redundancy: an investigation of the evolution of Australian elapid snake venoms. Toxins. (2016) 8:309. doi: $10.3390 /$ toxins 8110309

152. Aposhian HV. DMSA and DMPS - Water soluble antidotes for heavy metal poisoning. Annu Rev Pharmacol Toxicol. (1983) 23:193-215. doi: 10.1146/annurev.pa.23.040183.001205

153. Blaurock-Busch E. Comparison of chelating agents DMPS, DMSA and EDTA for the diagnosis and treatment of chronic metal exposure. Br J Med Med Res. (2014) 4:1821-35. doi: 10.9734/BJMMR/2014/6875 
154. Scatena R. Prinomastat, a hydroxamate-based matrix metalloproteinase inhibitor. A novel pharmacological approach for tissue remodellingrelated diseases. Expert Opin Investig Drugs. (2000) 9:2159-65. doi: 10.1517/13543784.9.9.2159

155. Albulescu LO, Xie C, Ainsworth S, Alsolaiss J, Crittenden E, Dawson CA, et al. A therapeutic combination of two small molecule toxin inhibitors provides broad preclinical efficacy against viper snakebite. Nat Commun. (2020) 11:1-14. doi: 10.1038/s41467-020-19981-6

156. Lewin M, Samuel S, Merkel J, Bickler P. Varespladib (LY315920) appears to be a potent, broad-spectrum, inhibitor of snake venom phospholipase A2 and a possible pre-referral treatment for envenoming. Toxins. (2016) 8:248. doi: 10.3390/toxins 8090248

157. Bittenbinder MA, Zdenek CN, Op Den Brouw B, Youngman NJ, Dobson JS, Naude A, et al. Coagulotoxic cobras: clinical implications of strong anticoagulant actions of African spitting Naja venoms that are not neutralised by antivenom but are by LY315920 (varespladib). Toxins. (2018) 10:516. doi: 10.3390/toxins 10120516
158. Solano G, Gómez A, Corrales G, Chacón D, Estrada R, León G. Contributions of the snake venoms of Bothrops asper, Crotalus simus and Lachesis stenophrys to the paraspecificity of the Central American polyspecific antivenom (PoliVal-ICP). Toxicon. (2018) 144:1-6. doi: 10.1016/j.toxicon.2018.01.01

Conflict of Interest: The authors declare that the research was conducted in the absence of any commercial or financial relationships that could be construed as a potential conflict of interest.

Copyright (c) 2021 Seneci, Zdenek, Chowdhury, Rodrigues, Neri-Castro, BénardValle, Alagón and Fry. This is an open-access article distributed under the terms of the Creative Commons Attribution License (CC BY). The use, distribution or reproduction in other forums is permitted, provided the original author(s) and the copyright owner(s) are credited and that the original publication in this journal is cited, in accordance with accepted academic practice. No use, distribution or reproduction is permitted which does not comply with these terms. 